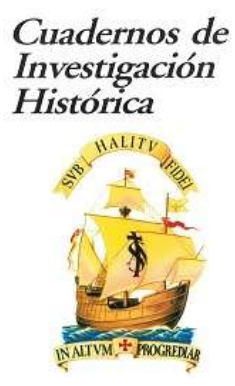

Cuadernos de Investigación Histórica No 37

La emperatriz Eugenia de Montijo: 100 años de la muerte de una española universal Año: 2020

DOI: https://doi.org/10.51743/cih.98

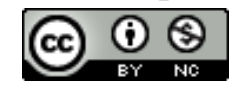

\title{
EL ESTILO NAPOLEÓN III: EL ESTILO DE LA OPULENCIA.
}

THE NAPOLEON III STYLE : THE STYLE OF OPULENCE

\author{
Miguel MúÑoz-Yusta del Álamo \\ Director de la Fundación Fernando de Castro
}

\begin{abstract}
RESUMEN
El estilo desarrollado bajo el reinado del Emperador Napoleón III, tanto en las Artes Decorativas, mobiliario cómo en la ornamentación de espacios, no obedece a un concepto de diseño creado específicamente para el Segundo Imperio, se trata de una recuperación de diferentes estilos generados en Francia en siglos anteriores. No es por tanto una estética nacida paralelamente al Imperio de Napoleón y Eugenia; es una recopilación de los grandes estilos franceses que en el pasado consiguieron crear fuertes tendencias decorativas tanto en Francia como en las cortes europeas.
\end{abstract}

Palabras clave: Napoleón III, estilo de la opulencia, Eugenia de Montijo 


\begin{abstract}
The style developed under the reign of Emperor Napoleon III, both in the Decorative Arts, furniture and in the ornamentation of spaces, does not obey a design concept created specifically for the Second Empire, it is a recovery of different styles generated in France in previous centuries. It is not therefore an aesthetic born parallel to the Empire of Napoleon and Eugenia; is a compilation of the great French styles that in the past managed to create strong decorative trends both in France and in European courts.
\end{abstract}

Key Words: Napoleón III, opulence style, Eugenia de Montijo

\title{
LA IDENTIDAD DEL ESTILO.
}

El eStilo Desarrollado bajo el reinado del Emperador Napoleón III, tanto en las Artes Decorativas, mobiliario cómo en la ornamentación de espacios, no obedece a un concepto de diseño creado específicamente para el Segundo Imperio, se trata de una recuperación de diferentes estilos generados en Francia en siglos anteriores. No es por tanto una estética nacida paralelamente al Imperio de Napoleón y Eugenia; es una recopilación de los grandes estilos franceses que en el pasado consiguieron crear fuertes tendencias decorativas tanto en Francia como en las cortes europeas.

Por tanto, el estilo Napoleón III recuperaba prototipos, técnicas o elementos decorativos propios de los estilos Luis XIV y Luis XV, Barroco y Rococó respectivamente. Según fue evolucionando la estética del Imperio se incorporó con fuerza el estilo Luis XVI, de base clasicista. Estos estilos decorativos en el pasado habían posicionado a Francia a la cabeza de las tendencias del interiorismo y mobiliario europeo tanto por su calidad o belleza como por la originalidad de sus diseños o prototipos. Estéticamente, el Segundo Imperio se construía sobre la consolidada gloria de los estilos franceses, cosechada durante los siglos XVII y XVIII en los que la supremacía de Francia en este sector era un reconocido hecho.

La naturaleza y el propio origen del estilo Napoleón III también llamado Segundo Imperio, nacía directamente en el eclecticismo estético. De esta forma, en 
un mismo espacio o pieza de mobiliario se incorporaban elementos propios del Barroco al Neoclásico pasando por el insinuante Rococó.

Los interiores representativos del periodo Napoleón III combinaban en gabinetes y salones, todos estos estilos del pasado suntuosamente reproducidos o interpretados. El mismo criterio decorativo se aplicaba a todo el conjunto, desde las boiseries o tremaux empleados en el recubrimiento de los paramentos verticales del salón, a los muebles de distintos estilos y formatos que invadían exageradamente el espacio. A todo éste ecléctico conjunto se sumaban las tipologías propias de la época que principalmente consistían en pequeñas butacas o "puff". El conjunto lo completaban las ricas tapicerías empleadas en el tapizado del mobiliario de asiento al igual que los importantes pabellones de cortinajes cargados de drapeados, borlas y pasamanerías, muy característicos de este periodo.

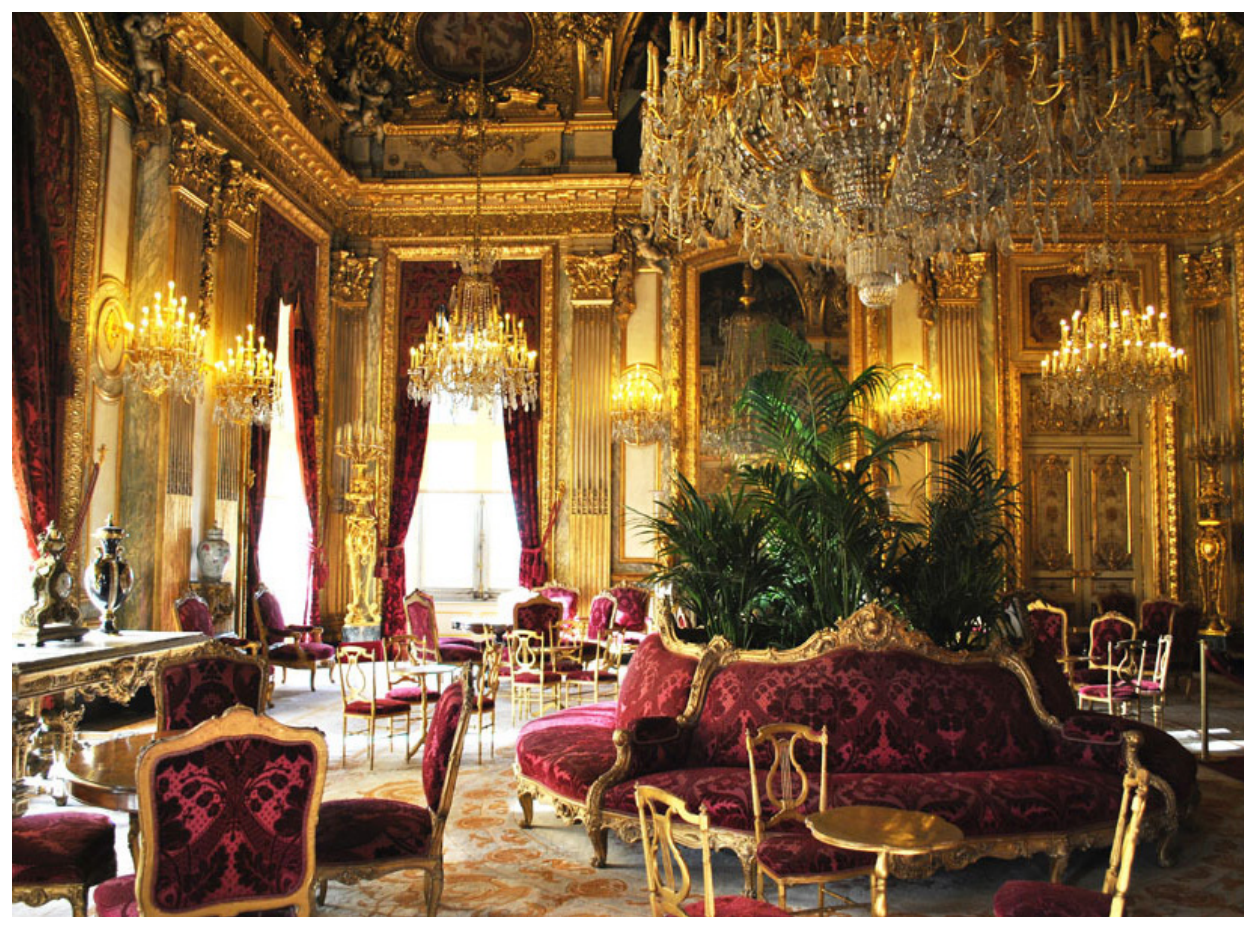

Apartamentos de Napoleón III en el Louvre.

Al gusto de la época, habría que añadir una cierta tendencia a la opulencia propia de un periodo social de desarrollo económico e industrial, por lo que el resultado era grandioso pero recargado. Los diseños basados en distintos elementos propios de tendencias o estilos del siglo XVIII tenían un resultado ecléctico, suntuoso pero exagerado. Este era el objetivo del estilo Napoleón III. 
La difusión internacional que se hacía del fastuoso Imperio Francés pronto posicionó a sus Artes Decorativas y el estilo Napoleón III como icono a seguir por medio mundo. Las grandiosas exposiciones internacionales celebradas en París, así como el eco de la atractiva y brillante vida social de la Corte Imperial consiguió que, a nivel internacional se considerase esta opulenta estética como imagen del éxito y la modernidad que, tenía en su eje central a Napoleón y Eugenia.

Desde la época de Luis XIV, Francia tenía claro el objetivo de imponer sus tendencias decorativas al resto de Europa. Esta política comercial, originaria de la época de Jean-Baptiste Colbert (1619-1683) intentaba, no sólo no depender de la importación de mobiliario y piezas suntuarias de otros países, sino exportar la propia producción francesa. Y para comercializar estos productos primero tenían que difundirlos y ponerlos de moda. Sus valores estaban en la exclusividad de las piezas, así como su novedoso diseño y la indiscutible alta calidad con que estaban realizadas. Este planteamiento comercial consiguió posicionar a Francia como cabeza de las tendencias de interiorismo y Artes Decorativas. El mismo concepto es el adoptado por la política imperial de Napoleón III a mediados del siglo XIX que apoyándose en los medios industriales de la época, consigue mantener el gusto francés como indiscutible referente estético internacional.

El estilo Napoleón III escenificaba sin pudor la opulencia de su identidad. Ese era su objetivo, reflejando con ello la prosperidad económica, social e industrial que Francia vivía y quería proyectar a mediados del siglo XIX. El Napoleón III o Segundo Imperio era el estilo del desarrollo económico e industrial francés, de las exposiciones internacionales, del gusto opulento de una sociedad pujante y cosmopolita, del desarrollo de la banca, del ferrocarril, de la nueva burguesía; en resumen: el estilo del éxito.

En pleno apogeo de la era industrial en Europa y con el objetivo de mostrar al Mundo el poder de la industria francesa, la imagen pública del Segundo Imperio era fundamental para posicionarse al frente de las demás potencias europeas y ostentar ser la cabeza visible de la industrialización. Con este objetivo, la potente imagen estética del Imperio Francés estaba minuciosamente medida para simbolizar el poder social y económico en un modo brillante, atractivo y aparatoso; lo que convirtió una vez más a París en el centro de modas y tendencias, volviendo a colocar a Francia como el eje de la vida social europea. La Emperatriz Eugenia, a pesar del recelo que generaba en el seno de familia Bonaparte y los bonapartistas, fue elegida por el Emperador para que fuese el epicentro estético y escénico del Imperio. 


\section{PARIS Y LA SOCIEDAD IMPERIAL.}

El plan de transformación urbanística de Paris ideado por el Emperador Napoleón III y el barón Georges-Eugène Haussmann (1809-1891) tenía como objetivo la transformación del corazón de la ciudad para convertirla en el centro socio económico de Francia y de Europa. Esta centralización de la actividad financiera y empresarial requería una imagen urbanística poderosa, de grandes escalas y riqueza estética que reflejara el poder del Imperio en la carrera europea por el liderazgo industrial. El objetivo era convertir París en la fastuosa imagen del todopoderoso Segundo Imperio Francés.

Estas reformas urbanísticas llevadas a cabo entre 1852 y 1870, también conocidas como "trabajos haussmanianos", llevaron a la construcción de lujosos hoteles y hotelitos, así como importantes edificios de viviendas destinados a ser residencia de la nueva y económicamente pujante burguesía francesa. Igualmente, el proyecto contemplaba la creación de espacios públicos suntuosos destinados a ubicar la brillante vida de la sociedad parisina. Todo este desarrollo urbanístico y constructivo aumento la demanda de interioristas, decoradores, tapiceros y ebanistas para crear espacios al nivel de tan importante arquitectura y que estuviese igualmente, a la altura de las necesidades estéticas de la nueva aristocracia.

Se vivía una fase de prosperidad nacional favorecida por el desarrollo de la industria y un periodo de fuerte especulación financiera que trajo como consecuencia el nacimiento de una nueva aristocracia, divergente y cosmopolita cargada con importantes fortunas que, desarrolló una gran tendencia al gusto por el lujo y la vida social. El desarrollo económico y social se había iniciado durante el reinado de Luis Felipe, llamado el rey burgués, entre 1830 y 1848, abriéndose un

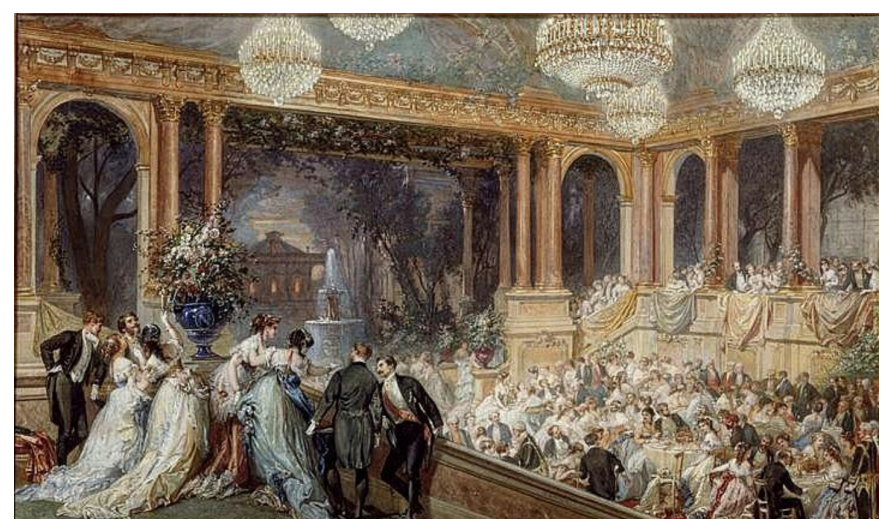

"Recepción en el Palacio de las Tullerias con motivo de la Exposición Internacional de 1867" obra de Henri Baron. Museo de Compiègne. 
ciclo expansivo que poco a poco empezó a convertir a Francia en el eje del mundo y que culminaría en el Segundo Imperio.

El desarrollo industrial de mediados del siglo XIX, potenció el auge de la burguesía francesa tanto en lo económico como en lo social, provocando una pérdida progresiva del poder de la nobleza tradicional. La naciente y poderosa burguesía que, en el fondo deseaba equipararse con la antigua nobleza, tenia cierto empeño en conseguir un título, bien por concesión o por matrimonio, lo que daría paso a la aparición de una nueva aristocracia. Para situarse socialmente, había una gran necesidad de enriquecerse y eso llevaba a un comportamiento especulativo y visualmente ostentoso. La nueva aristocracia era una complicada mezcla social compuesta por industriales, nuevas fortunas, nobleza napoleónica, títulos recién nacidos, banqueros, funcionarios, intelectuales, grandes bellezas, damas que sentenciaban moda y formas sociales... todos ellos con un objetivo: el de brillar. Y esta disposición al lujo fastuoso fue generando la estética atractiva y brillante del Estilo Napoleón III que, no sólo era una forma de ornamento sino, también de vida. Una noche de baile en las Tullerias nos recordaría más al brindis de "La Traviata" de Verdi en su primer acto que a una corte imperial con rigor político. Como dijo el conde Emile Fleury tras la caída del Imperio: ..."no fue un imperio como debe ser, ipero cómo nos divertimos!” ...

Los hábitos sociales del nuevo Paris evolucionaban según las necesidades de sus habitantes y del cada vez mayor número de visitantes que frecuentaba la ciudad. Proliferaba la suntuosa vida social y con ella los teatros, restaurantes o cafés, todos ellos decorados con esmero. Surgieron grandes tiendas y elegantes establecimientos destinados a satisfacer las necesidades de una rica y delirante burguesía con la íntima necesidad de ir siempre a la moda, ser distinguidos y

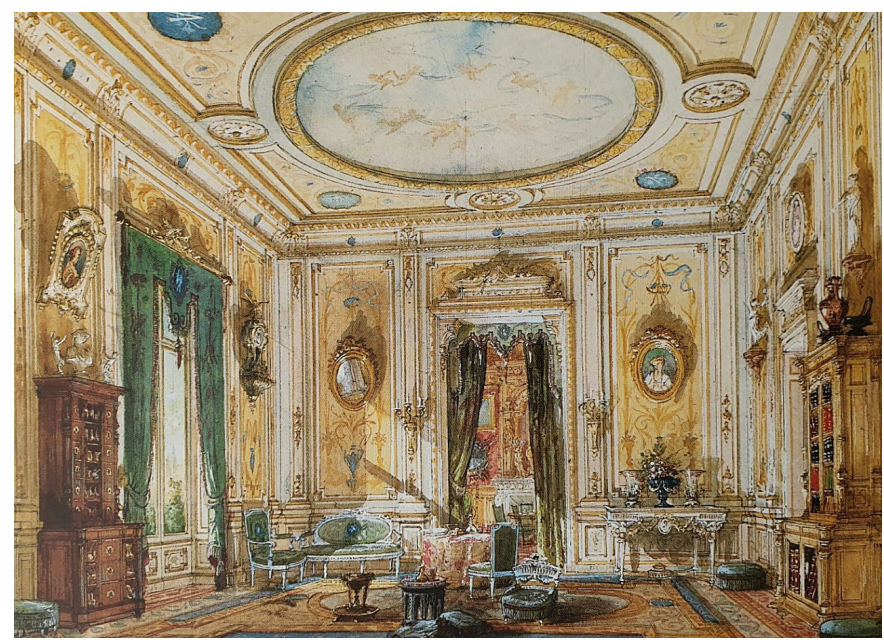

Salón de la Princesa Matilde Bonaparte”, acuarela realizada en 1867 por Charles Giraud. 
sobre todo hacer muestra pública de su poderosa posición. La demanda social multiplicó la aparición de casas de moda, sastres o joyeros y, de la misma forma también proliferaron los talleres de ebanistas, tapiceros y estudios de decoración. El auge social y los "trabajos Haussmanianos" llenaron Paris de nuevas y lujosas viviendas que, junto a la pujante industria francesa, marcaron un momento importante en los proyectos de interiorismo, la decoración y del mueble.

\section{ESTILO DEL ANTI ESTILO.}

El Estilo Napoleón III desarrollado entre 1852 y 1870, tuvo una gran proyección internacional dada la buena difusión que se hizo de las Artes Decorativas francesas generadas en este periodo. El interés de la política imperial por conseguir liderar la industria europea favoreció y potenció la industrialización de las Artes Decorativas. Francia, ya había sido cabeza en este ámbito durante el siglo XVIII, por ello en los objetivos económicos del Segundo Imperio estaba seguir liderando el sector. Entre las circunstancias que indiscutiblemente universalizan al Napoleón III destaca la exportación masiva de mobiliario, textiles, bronces o porcelanas facilitada por la industrialización de los medios de transporte marítimos o el ferrocarril, todo ello acentuado por el reclamo mundial que suponían las exposiciones internacionales de París celebradas con gran fasto en los años 1855, 1861 y 1867. De la misma forma, la elegante imagen social proyectada por el Imperio, consiguió posicionar el gusto por lo francés como indiscutible modelo estético en el mundo occidental de mediados del siglo XIX.

El estilo Napoleón III, definido como "el estilo del anti estilo" por ser una tendencia decorativa sin apenas diseño específico propio y construirse sobre la interpretación de estéticas desarrolladas en siglos anteriores. El estilo Napoleón III tenía además una gran tendencia a deformar o exagerar las piezas reproducidas para conseguir con ello un efecto de mayor suntuosidad. No sólo recuperaban estilos del siglo XVIII, sino que además, mezclaban sus elementos entre sí a capricho, creando verdaderos híbridos sin un estilo determinado. Por ello es "el estilo del anti estilo". Cierto es también que todas estas mezclas desproporcionadas de técnicas o elementos dieciochescos consiguieron darle una entidad propia al Napoleón III. En realidad, el objetivo estaba en demostrar la capacidad de la industria para la fabricación o reproducción de muebles por encima de una finalidad exclusivamente estética o creativa. Industrializar el pasado era la intención incluso, masificar la producción consiguiendo hacer socialmente accesible algo que hasta el momento había sido para uso exclusivo de unos pocos. El Napoleón III es el estilo de la Revolución Industrial. 

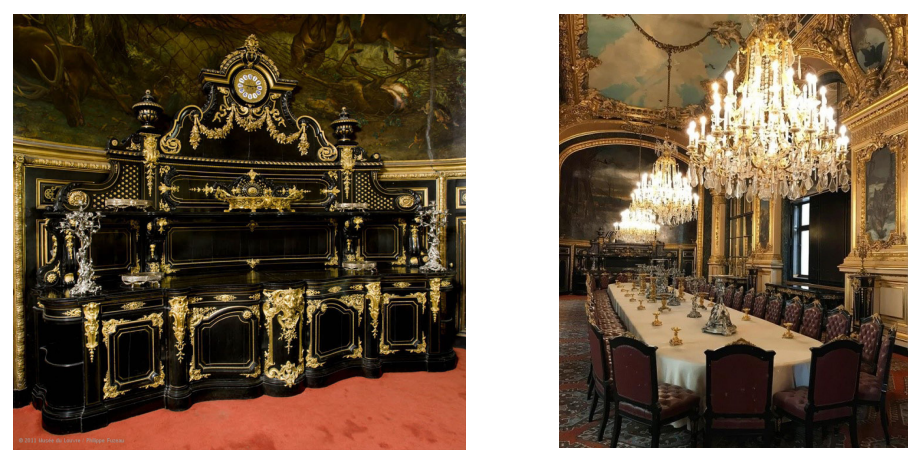

“Grand buffet”. Apartamentos de Napoleón III. Museo del Louvre. Paris.

La recuperación de "glorias del pasado" se puede entender dentro del sentimiento nacionalista o romántico tan propio de la época y no exento de objetivos concretos dentro de la política del Segundo imperio. La recuperación del pasado estético es una característica propia del Romanticismo que intentaba ensalzar periodos brillantes del interiorismo y las Artes Decorativas francesas desarrollados siglos atrás y que, habían conseguido la admiración de cortes y príncipes europeos. Este sentimiento romántico y nacionalista, empezó a evolucionar paralelamente al principio del proceso de industrialización de la Artes Decorativas francesas iniciado durante el reinado de Luis Felipe de Orleans, de 1830 a 1848. En este periodo comenzaron a interpretarse estilos y tipologías de mobiliario propias del Renacimiento Francés, concretamente del estilo Enrique II o del Gótico. La

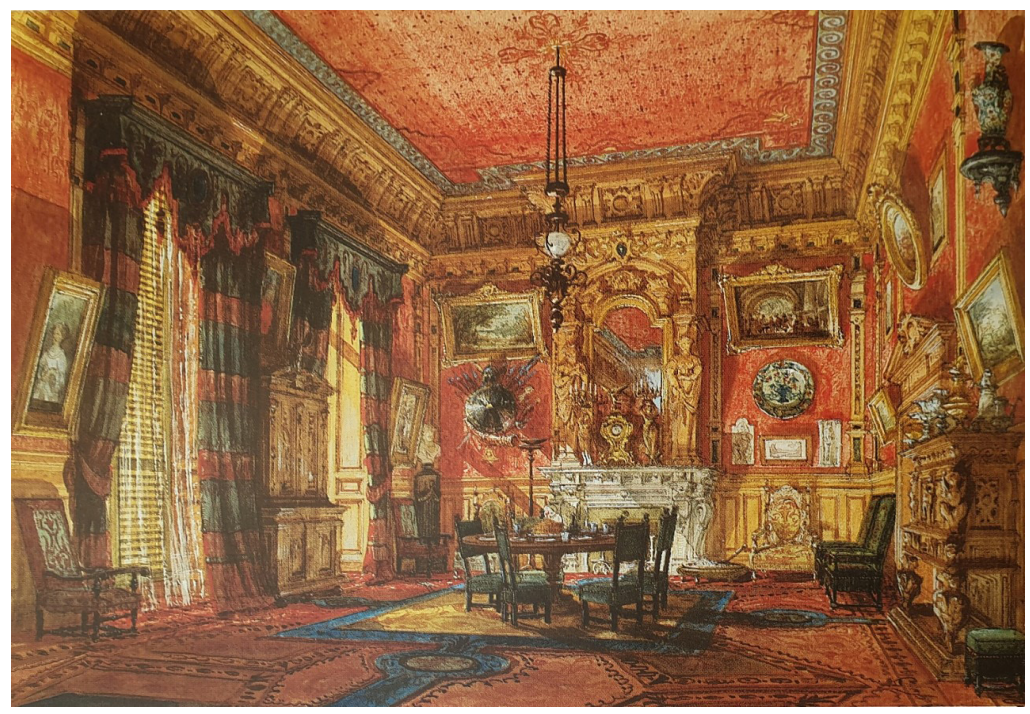

"Comedor de la Princesa Matilde en su hotel de la calle Courcelles". Obra de Charles Giraud en 1867. Museo de Artes Decorativas de Paris. 
restauración de emblemáticos edificios parisinos como era el palacio del Louvre o la Catedral de Notre Dame, concurso ganado por Viollet-le-Duc (1814-1879) en 1845, acentuó la moda a recuperar tendencias artísticas del pasado. La influencia del arquitecto Viollet-le- Duc, puso de moda el mobiliario de inspiración gótica. En la acuarela firmada por Charles Giraud, realizada en 1867 que reproduce la "salle à manger de la princesse Mathilde, rue de Courcelles" (Musée des Arts

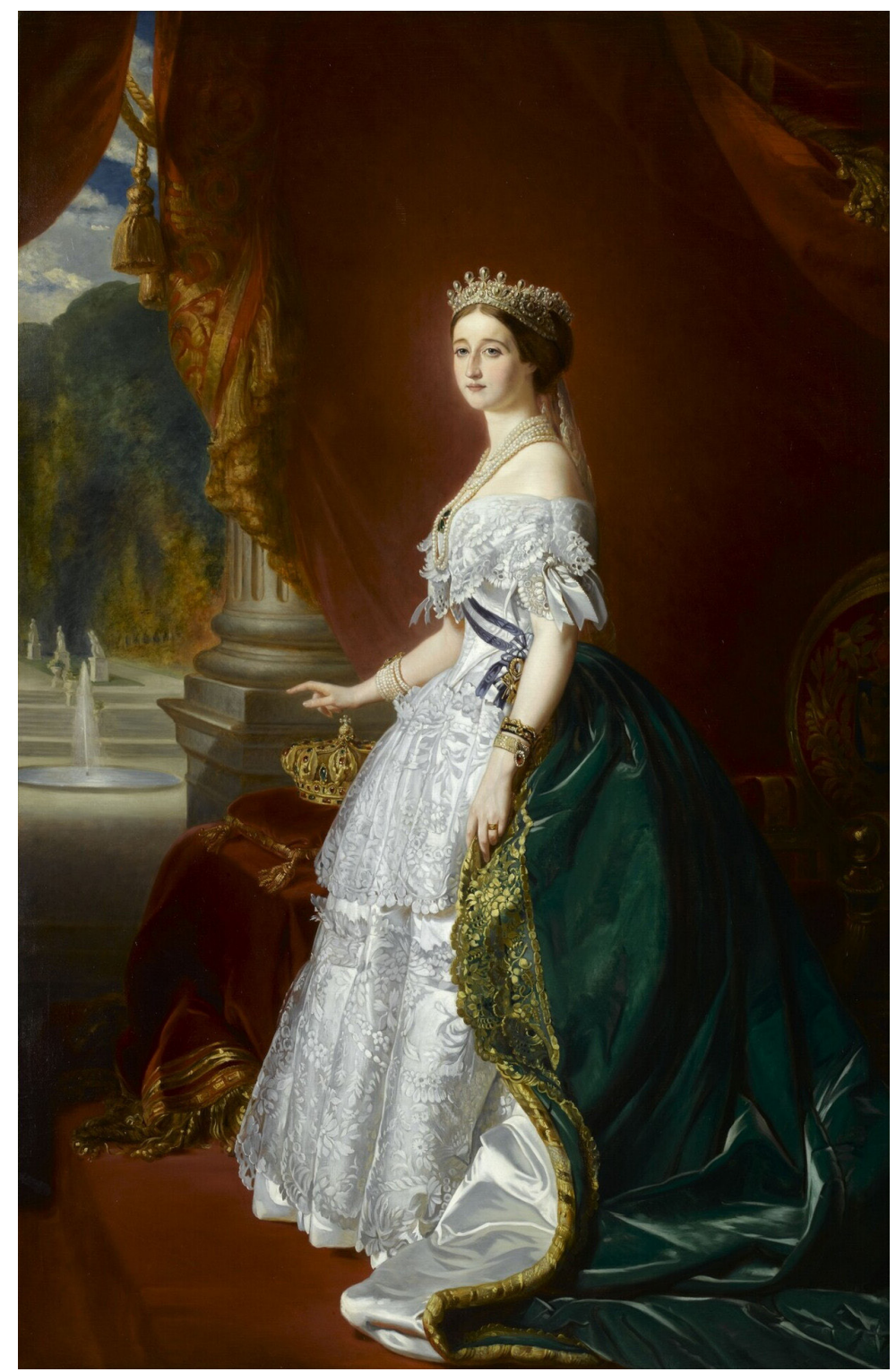

“Eugenia” 1855. François Xavier Winterhaiter (1805-1873.) 
décoratifs. Paris) podemos apreciar dentro del eclecticismo historicista propio de la época, un aparador o "bufé" de gran formato estilo Renacimiento francés.

De este sentimiento nostálgico propio del Romanticismo y del reinado de Luis Felipe se evolucionó al periodo de Napoleón III. Siguiendo con este mismo criterio se "resucitaron" estéticas características de los siglos XVII y XVIII, el mejor momento de las Artes Decorativas francesas. Con ello, resurgen con fuerza los estilos Luis XIV, Regencia, Luis XV o Luis XVI que van a convivir con los ya "resucitados" estilos Gótico o Enrique II. Se recuperan tipologías propias del Barroco, del Rococó o del Neoclasicismo así como, trabajos característicos de grandes ebanistas del pasado como Andreé Charles Boulle (1642-1732) o Jean-Henri Riesner (1734-1806).

\section{Los GUSTOS DE EUGENIA.}

El estilo Luis XVI, como todo lo relacionado con la época en la que reinaba María Antonieta (1755-1793) despertaba gran atracción en la emperatriz Eugenia, que siempre demostró un singular interés por este estilo. Sin duda, es el gusto de la Emperatriz el que volvió a poner de moda al estilo Luis XVI, caído en el olvido desde la época de la Revolución Francesa.

Mucho se ha escrito sobre la atracción que María Antonieta ejercía en la Emperatriz Eugenia y, aparte de posibles comparaciones en sus respectivos papeles políticos, si es verdad que Eugenia sentía desde niña mucho interés por la figura

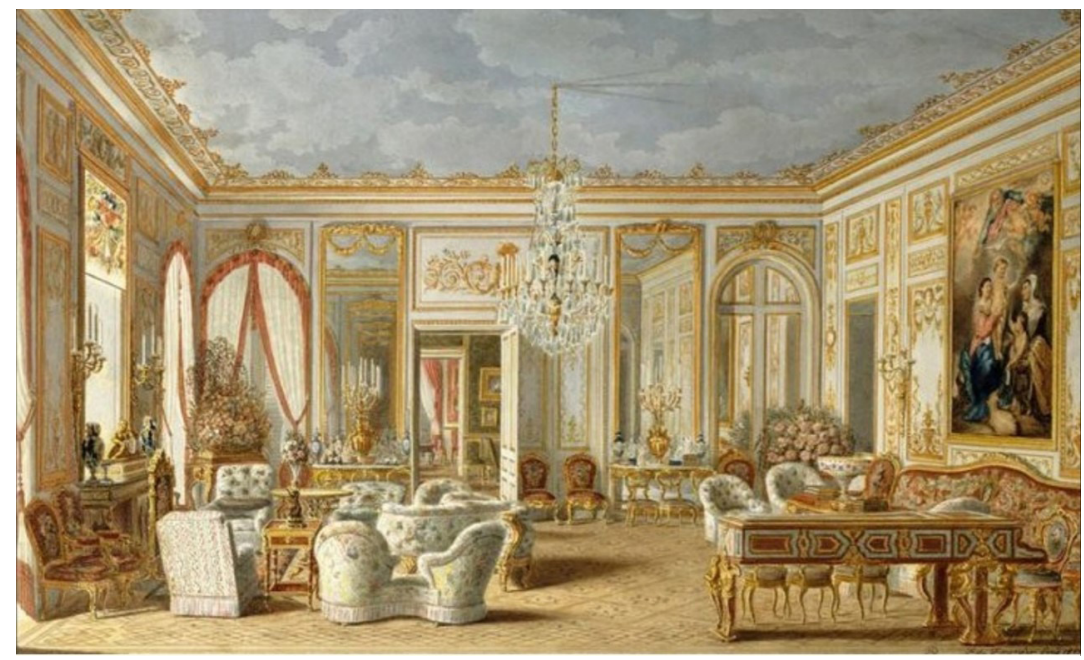

"Gran salón del castillo de Saint Cloud". Apartamentos de la Emperatriz. Obra de Fortuné de Fournier realizada en 1860. Museo Castillo de Campiègne. 
de la guillotinada reina de Francia y posiblemente esta circunstancia la llevase a sentir predilección por la estética de su reinado, el estilo Luis XVI.

La propia Eugenia en la vejez recordaba su primer encuentro con María Antonieta y la fascinación que en ella le causó siendo niña En una mañana de septiembre de 1838 con su madre la condesa de Montijo y acompañadas de la institutriz británica Miss Flowers, fueron a pasear por el parque Versalles y al "Petit Trianón". En este entorno fue dónde le hablaron por primera vez de la malograda Reina de Francia, lo que despertó en la joven Eugenia una verdadera atracción por la romántica figura de María Antonieta que le acompañará toda su vida.

Si analizamos las acuarelas que en 1860 realizó Fortuné de Fournier (17981894), del "cabinet de travail de l'Impératrice Eugénie à Saint-Cloud " y "Grand salón du château de Sanit-Cloud" (museé nacional du château de Comiégne) podemos observar además de la tendencia ecléctica a la mezcla de estilos de mobiliario, una supremacía decorativa en elementos, molduras y boiseries inspiras en el Luis XVI. Igual pasa con muchas de las piezas de mobiliario que se encargaron para Villa Eugénie, tales como sillerías, cómodas o armarios bajos "d`entre-deux" tan característicos del Napoleón III, todo ello inspirado en el estilo propio del reinado de María Antonieta.

En base a ello, y sobre el análisis de la posible existencia de un estilo "Empératrice Eugénie" según defienden algunos autores, sí podríamos atribuir a los gustos personales de la Emperatriz la fuerte presencia del estilo Luis XVI en los

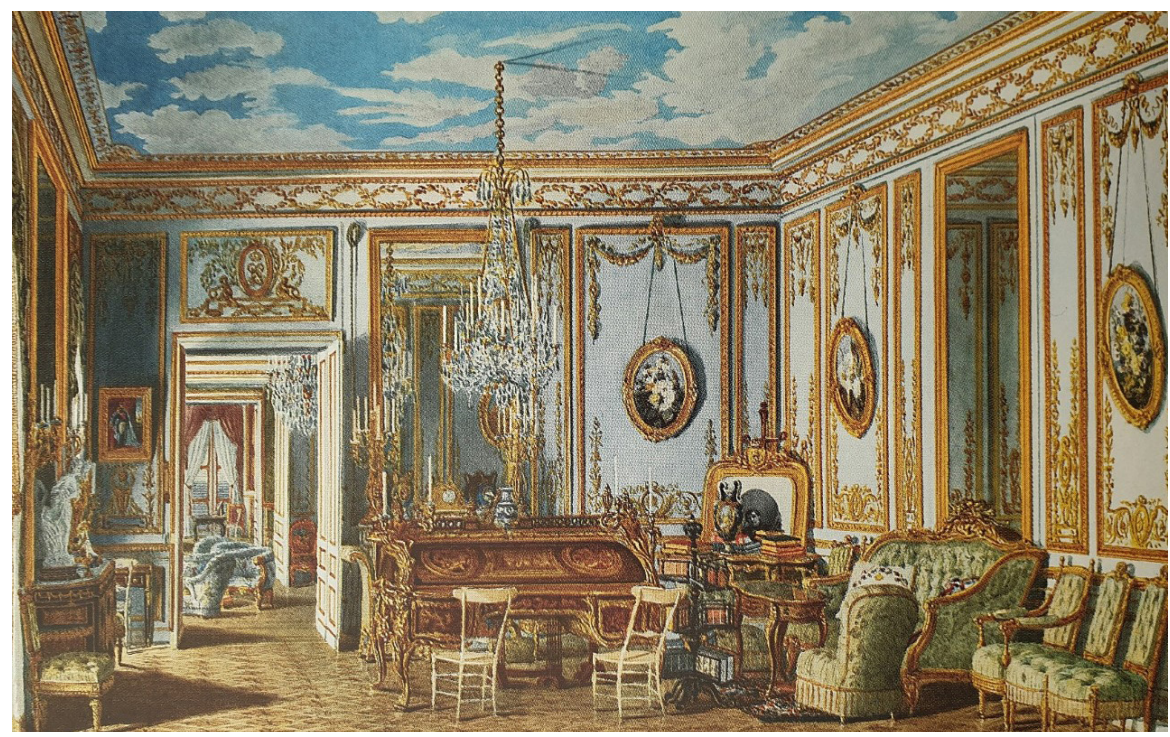

"Despacho de trabajo de la Emperatriz Eugenia en Saint Cloud. Obra de Fournier en 1860. Museo Castillo de Compiègne. 
espacios decorados bajo su supervisión. En realidad, la Emperatriz Eugenia, realizaba encargos de piezas inspiradas o que reproducían prototipos característicos del siglo XVIII, a diferencia de otras soberanas francesas como la propia María Antonieta, para la que sí se creó un estilo con identidad propia. Hablar de un estilo "Eugénie" sería un poco inexacto dado que no se crea un estilo específico para ella. Independientemente, si hay que reconocer el papel fundamental de la Emperatriz Eugenia creando modas y tendencias que serán la base estética del estilo Napoleón III generado durante su reinado.

La Emperatriz tenía cierto gusto por las antigüedades incorporándolas en los espacios que de forma cotidiana habitaba. Atraída por el romanticismo que encierra la historia propia de cada mueble y objeto, recuperó para su uso personal piezas guardadas en los guardamuebles de Versalles y en el Petit Trianon que habían pertenecido entre otros monarcas a la Reina María Antonieta. Si estudiamos la acuarela realizada por Fournier del "cabinet de travail" de la Emperatriz reproduciendo sus apartamentos de Saint Cloud, encontramos en ella representado el gran bureau que perteneció al Rey Luis XV de Francia, obra de los ebanistas dieciochescos Oeben y Riesener, dispuesto para uso personal y cotidiano de la Emperatriz. Igualmente, en este conjunto de acuarelas realizadas por Fournier en 1860, concretamente la que recrea el dormitorio de la Emperatriz, aparece el conocido "cabinet de travail" que había pertenecido a María Antonieta.

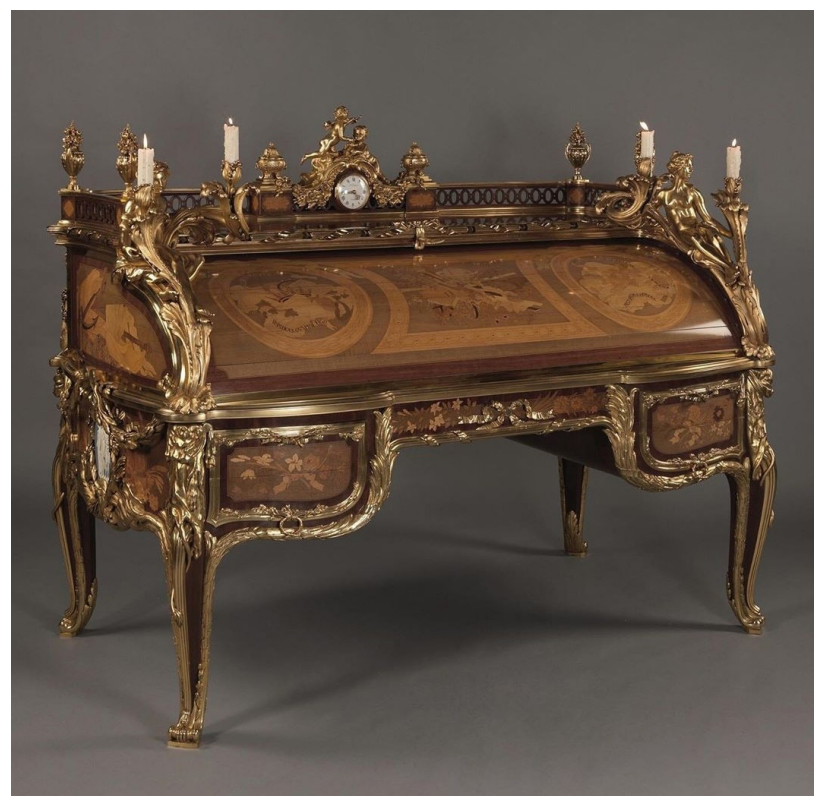

"Gran bureau de Luis XV". Museo Castillo de Versalles 
Esta tendencia a la recuperación y uso de antigüedades caló en la sociedad parisina del Segundo Imperio favoreciendo con ello, la proliferación de anticuarios y marchantes que empezaron a abrir sus puertas en Paris a mediados del siglo XIX. La comercialización de mobiliario y piezas realizadas en siglos anteriores, cargadas de pátina e historia, generó el llamado gusto "de lo antiguo" que tuvo gran aceptación en el seno de una nueva aristocracia sedienta de lujos del pasado.

Eugenia, era el indiscutible epicentro estético del Segundo Imperio y como tal, sus gustos o encargos pronto se convertían en tendencias que todo Paris imitaba.

\section{CARRERA POR EL DOMINIO DE LA INDUSTRIA: MOBILIARIO E INDUSTRIA.}

La gran demanda decorativa que provocó el nuevo plan urbanístico de Paris junto al crecimiento de la burguesía francesa, generó un importante auge en el sector de la Artes Decorativas. La necesidad de amueblar y decorar ricamente las casas siguiendo los cánones estéticos de la época era fundamental en la sociedad del Segundo Imperio. Todo ello creó una gran demanda de todo tipo de oficios, mobiliario y elementos; desde papeles pintados, doradores o pintores decorativos, a carpinteros y tallistas, tapiceros o ebanistas todo un pequeño regimiento de oficios para conseguir suntuosos espacios que habitar.

La creciente demanda ornamental surgida durante el Segundo Imperio se desarrolló atendiendo a las necesidades de las diferentes escalas sociales. Esta circunstancia dio lugar a que la oferta en Artes Decorativas y suntuarias estuviese realizada en calidades muy diferentes adaptables a los distintos presupuestos. Por lo cual, podemos clasificar la oferta de Artes Decorativas y mobiliario en tres escalas diferentes según su calidad: la primera escala acogería a las piezas del más alto nivel de ejecución, tanto en calidad como en exclusividad, realizadas siguiendo los sistemas tradicionales de los talleres de ebanistería y ejecutadas por artistas de gran prestigio. Estas piezas estaban destinadas a la Casa Imperial, las exposiciones internacionales o la alta aristocracia. Las dos siguientes escalas, trabajaban dentro de un proceso industrializado diferenciándose igualmente por su calidad: alta o media, destinados respectivamente a la alta o media burguesía, todo era cuestión de presupuestos. Podría incluirse también en esta clasificación un cuarto grupo de producción de Artes Decorativas, igualmente industrializadas, pero de nivel mucho más bajo que reproducía las piezas en escasa calidad destinadas a grupos sociales más modestos.

La industrialización y la demanda social masificó la producción de muebles y elementos decorativos en el periodo Napoleón III que, además se exportaron en grandes cantidades a medio mundo. Aún hoy en día, es sencillo encontrar 
muebles o porcelanas de esta época a muy buen precio en anticuarios o casas de subasta.

Dentro del mobiliario Napoleón III, se tendía a reproducir fielmente tipologías dieciochescas o, igualmente se interpretaban mezclando en ellas elementos ornamentales de diferentes estilos. También se crearon algunas tipologías propias del periodo, aunque se diseñaron siguiendo cánones de otras épocas mezclando libremente y con poco rigor estético, técnicas o elementos decorativos. En ocasiones el resultado, aunque pudiese recordar conceptos de los estilos luises, era francamente ecléctico. Había igualmente una gran tendencia a la opulencia por lo que, en ocasiones muchos de los ejemplares de mobiliario, rompían las escalas originales de las piezas.

En el Segundo Imperio, en plena era de la industrialización, lo importante era demostrar el valor de la pujante industria frente a los sistemas tradicionales de producción. Se tenía el objetivo de crear un arte industrializado que pudiera demostrar el poder creativo de la máquina, y con ello la posibilidad de industrializar las Artes Decorativas. Por eso, se le daba más valor al resultado de la industrialización sobre un objeto o mueble que a la estética de la pieza, la individualidad o el diseño en sí.

\section{EBANISTAS Y TALLERES DE EBANISTERÍA.}

Las circunstancias hicieron que a mediados del siglo XIX los talleres de ebanistería, más o menos industrializados, proliferaran en París poniendo a la venta mobiliario para todos los gustos. Al igual, florecieron de forma significativa comercios especializados que ofrecían desde papeles pintados franceses o de importación a las últimas novedades en telas y pasamanerías o barrocas porcelanas decoradas por Jacob Petit (1796-1865).

De este periodo destacan grandes ebanistas que trabajaron directamente para la decoración de las residencias imperiales bajo la supervisión de la Emperatriz Eugenia.

Alexandre-Louis Bellangué (1799-1863) miembro de una destacada dinastía de ebanistas franceses, heredó el taller de su padre Pierre-Antoine Bellengué (1758-1837) que había sido proveedor de mobiliario del emperador Napoleón I. Al ponerse al frente de la empresa familiar, con una visión comercial moderna y diferente a la de su padre, modernizó los sistemas de trabajo consiguiendo con ello una extraordinaria producción. Se especializó principalmente en la reproducción de mobiliario de diferentes estilos franceses del siglo XVIII destacando sobre todo por sus piezas de inspiración en los estilos Luis XIV y Luis XV. Aunque se retiró en 1855 su taller continuó prolíferamente activo durante el reinado de 
Napoleón y Eugenia. Alexandre Bellangué se especializó en trabajos basados en el estilo y la marquetería de Boulle que era muy del gusto de la Emperatriz por lo que se le hicieron importantes encargos de mobiliario destinados a los palacios Imperiales y la Villa Eugenia en Biarritz. Ballangué realizó "cabinets d'entredeux" en estilo Luis XVI con marqueterías metálicas de "parte y contraparte" estilo Boulle que tuvieron gran repercusión en la época.

Otro de los grandes proveedores imperiales de piezas de mobiliario basadas en estilos del siglo XVIII, fue Guillaume Grohé (1808-1885) de origen alemán. Junto con su hermano comenzaron haciendo mobiliario de estilo Neogótico y Neoegipcio que presentaron en la Exposición Internacional de 1834 bajo el reinado de Luis Felipe. Ya durante el Segundo Imperio en la Exposición de las Artes Industriales Francesas de 1861, expusieron obras basadas en los estilos luises franceses que fueron muy aclamadas por su alta calidad de ejecución. En el taller de los hermanos Grohé trabajaban artistas muy distinguidos de la época: marqueteros de la categoría de Liénard o el afamado broncista Fannières que contribuían con su arte a dar exclusividad a las piezas diseñadas. Guillaume Grohé, especializado en la reproducción de mobiliario inspirado en el estilo Boulle o en la obra de Riesener, fue proveedor de la Corte Imperial y especialmente reproducía piezas de estilo Luis XVI para la Emperatriz Eugenia desde el año 1862. Muchos de los encargos que la Emperatriz hizo a Grohé, se guardan hoy en Compiègne, el castillo de Fontainebleau y en parisino museo de Carnavalet.

Entre los ebanistas que trabajaban para la Casa Imperial, no sólo como proveedores de mobiliario sino ejecutando proyectos completos de interiorismo, está la saga de los Jeanselme. Joseph Pierre Francois Jeanselme (m. 1860), adquirió la importante firma "Jacob-Desmalter" en 1847 modernizando e industrializando sus sistemas de producción de mobiliario, llegando a crear uno de los talleres de ebanistería más importantes y productivos de Paris. Su crecimiento fue tan grande que en 1855 contaban con más de 300 operarios en activo. Realizaba importantes piezas inspiradas en el estilo Boulle, especializándose en este tipo de marquetería al igual que, en piezas de estilo Luis XVI siguiendo los gustos de la época. Con la incorporación en 1863 de Charles Joseph Marie Jeanselme (1827-1871) como cabeza de la empresa familiar se constituye una de las sagas más importantes de ebanistas e interioristas de la época que continuó su actividad hasta 1893, siguiendo siempre los patrones estéticos del Napoleón III. Entre los años 1856 y 1857 recibió importantes encargos de mobiliario y sillerías por parte de la Emperatriz Eugenia destinados al castillo de San Cloud y Fontainebleau. Así mismo tras el éxito obtenido con los primeros trabajos realizados para la Corte Imperial, la firma de los Jeanselme recibió en 1859 el encargo de decorar y amueblar el castillo de Compiègne. En la Exposición Internacional de Paris 
celebrada en 1867 la ya afamada casa de los Jeanselme presentó un conjunto de piezas de mobiliario que cosechó un importante éxito comercial, siendo su alta calidad de ejecución ensalzada por parte de la crítica especializada. La firma de los Jeanselme realizó destacados encargos para los hoteles o casas de la alta aristocracia parisina instalada en torno a los Champs-Elyséss, el boulevard Voltaire o la avenue de L Opera. Entre su distinguida clientela figuran otros miembros de la familia del Emperador como el Príncipe Napoleón Bonaparte que encargo piezas

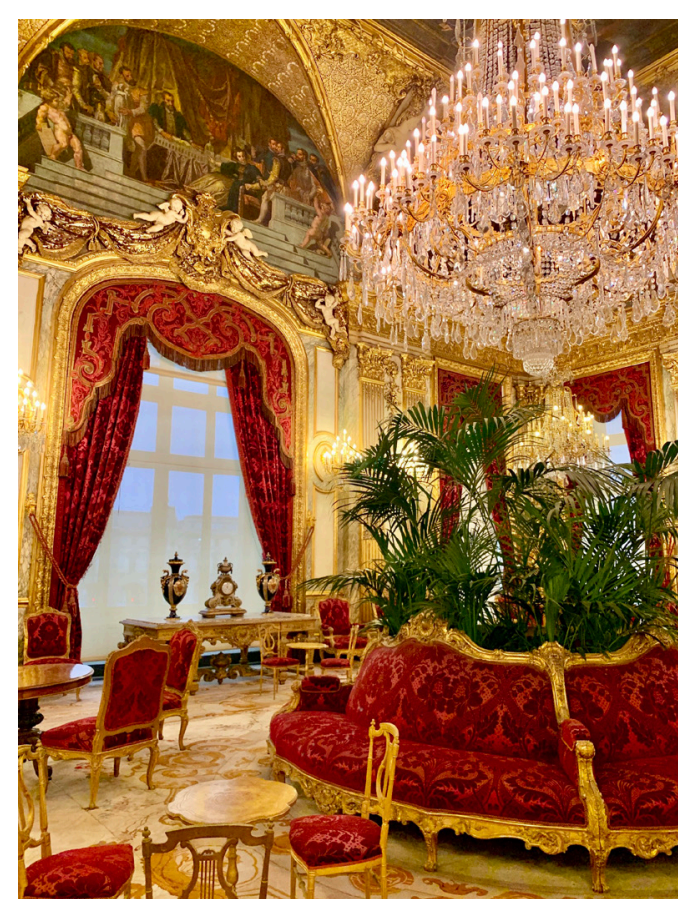

"Apartamentos de Napoleón III" Museo del Louvre. Paris. destinadas a sus estancias del Palais Royal o de la Princesa Mathilde Bonaparte para su hotel en la rue de Courcelles donde estuvo ubicado uno de los más destacados salones culturales y artísticos del Segundo Imperio.

La expansión social que se vivía en París a mediados del siglo XIX favorecía con mucha fuerza el trabajo de diseñadores, ebanistas o tapiceros fomentando que sus talleres proliferaran por toda Francia. Trabajando en Paris destacan muchos y distinguidos profesionales del diseño o interiorismo: Pierre Manguín (1815-1869) que realizó grandes proyectos en los hoteles de los Champs-Elyséss como el de la Marquesa de Paiva. Trabajando para el Príncipe Napoleón Bonaparte, Charles Rossigneaux (1818-1907) para quién realizó su afamada villa Pompeyana en 1860. Julien Nicolás Rivart, fallecido en 1867, diseñaba maravillosas piezas inspiradas en muebles del siglo XVIII que chapeaba en maderas claras, preferentemente el palisandro o el "bois de Rose" utilizando bronces y placas de porcelana, aunque en ocasiones, sobrepasando en ornamentos la esencia de los muebles dieciochescos en que se inspiraba.

Prestigioso tallista fue Alexandre- Georges Fourdinois (1799-1871), especializado en reproducir modelos propios del Renacimiento francés realizados en madera de roble o nogal. También destacable el trabajo del tallista y dorador Michael-Victor Cruchet (1815-1899) que conto con el reconocimiento de la Casa Imperial y la aristocracia parisina. Realizó gran cantidad de sillerías y 


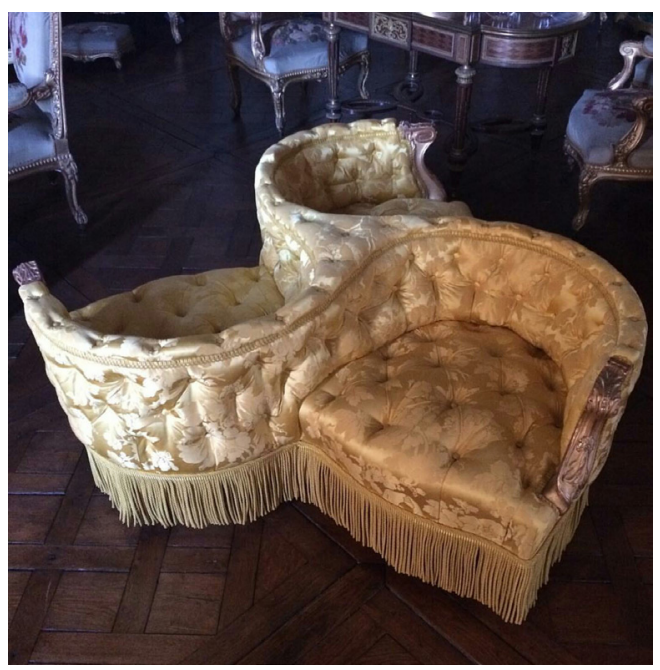

“indiscret” 1859. Museo de Compiègne.

consolas destinadas al castillo de Saint Cloud, así como para Fonteinebleau, ejecutadas en madera tallada y dorada siguiendo modelos Luis XIV, Luis XV y especialmente Luis XVI bajo encargos concretos de la Emperatriz Eugenia. Instalado en París en torno al año 1836 fue uno de los más afamados talleres del Segundo Imperio proyectándose la demanda de su obra a lo largo de la segunda mitad del siglo XIX.

Entre los talleres más industrializados establecidos en París durante el Segundo Imperio y concreta-

mente en la rue Saint-Honoré, destaca Luis-Auguste Beurdeley (1808-1882) igualmente especializado en reproducción de prototipos de mobiliario característicos del siglo XVIII.

Tanto los hermanos Charón como Julies Fossey, hicieron piezas concretas para la Emperatriz: un joyero con apliques de porcelana sobre las puertas realizadas en "bois de violette" ejecutado por los primeros y, Julies Fossey que realizó una "toilette"

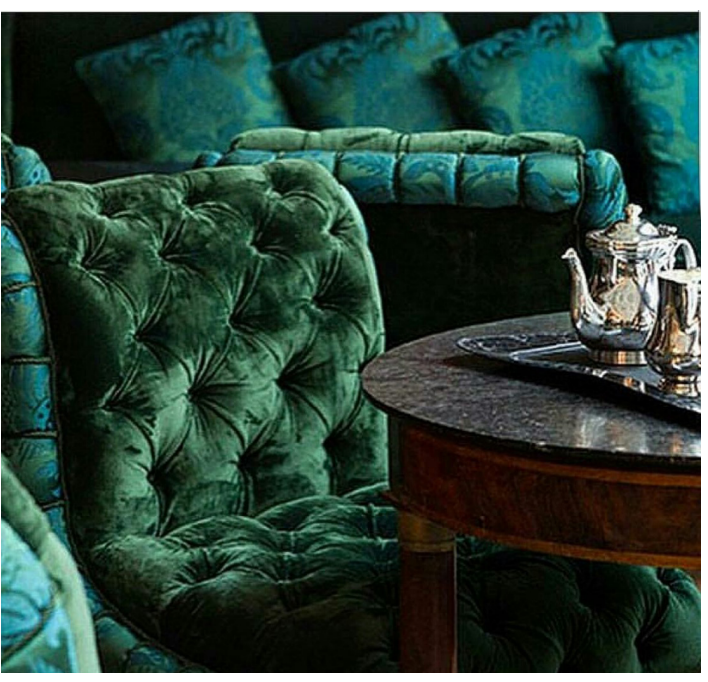

Butacas Napoleón III.

siguiendo modelos del estilo Luis XVI con placas de porcelana sobre estructuras de madera tallada y dorada.

Destaca el ebanista Alexandre Roux (1837-1881) por la difusión internacional que hizo del mobiliario Napoleón III ya que, en 1837 se instaló en Nueva York asociándose con su hermano Frederic Roux bajo el nombre de "Roux \& Company" (1857-1881) montando importantes talleres que situaron en Broadway. Realizaban desde la década de 1850 muebles inspirados en el estilo Luis XVI siguiendo los gustos de la Emperatriz Eugenia. Desde 1860 incorporaron en sus muebles placas 
de porcelana realizadas siguiendo modelos de la manufactura de Sevrés diseñados para la Reina María Antonieta en el siglo XVIII. Este mobiliario, de gran calidad y muy del gusto de la época, cosechó un importante éxito dentro de la sociedad newyorkina comercializándose por el resto de los Estados Unidos y universalizando con ello el estilo Napoleón III. Igualmente, la "Roux \& Company" importaba mobiliario realizado en Francia para ser comercializado en Nueva York.

\section{TAPIZADOS Y TAPICERÍAS.}

Una de las características más destacables de los interiores realizados durante el Segundo Imperio fue el uso prominente de entelados, tapicerías así como de grandes pabellones de cortinajes cargados de pasamanerías, drapeados o "bandeaux". Esta tendencia ornamental de la que en ocasionas se abusaba, terminó por ser un punto de identidad en los interiores de Napoleón III.

La Revolución Industrial, desde sus inicios había evolucionado de forma radical el sector textil circunstancia que aumentó la oferta de telas en el mercado y como consecuencia, abarató su costo. Los talleres textiles proliferaron en Europa de forma significativa, por lo que el mercado evoluciono mucho pasando a ofrecer gran variedad de tejidos de calidad con diseños diversos y ricos estampados, destinados a embellecer el interior de las opulentas casas de la aristocracia francesa. Los textiles y tapicerías empezaron a tomar un gran protagonismo en los proyectos de espacio interior realizados en este periodo.

Desde el siglo XVI habían florecido en ciudades como Aubusson o Felletin distintos grupos de telares de alto y bajo lizo que, durante el periodo Napoleón III se dedicaron a reproducir diseños del siglo XVII y XVIII. Estos tejidos estaban destinados a caídas de cortina y en gran parte a tapicerías para mobiliario de asiento. La afamada fábrica de Beauvais se dedicó igualmente a la reproducción de cartones dieciochescos destinados a la decoración de interiores. Las grandes manufacturas como Gobelinos mantuvieron sus sistemas de producción tradicional, aunque en 1825 se fusionó con la fábrica de alfombras de Savonneire que había sido fundada por Luis XIII en 1627, dedicándose a producir durante el Segundo Imperio gran cantidad de alfombras de nudo en alta calidad.

Destaca la figura de Henry Penon (1830-1908) quién gozó de gran prestigio como diseñador de conjuntos textiles, pabellones de cortinas cargados de ricas pasamanerías. Participó con sus hábiles y complicados diseños de cortinajes en los más importantes proyectos de interiores del Segundo Imperio. La riqueza de sus conjuntos se acercaba a la teatralidad contribuyendo de forma definitiva con la opulencia del estilo Napoleón III.

En este sentido y paralelamente al desarrollo del textil, empezó a proliferar el 
mueble de asiento totalmente tapizado. La presencia de pequeñas butacas, "bornes", "mileu", "confident et indiscret" o "poff" empezó a multiplicarse en los salones del Segundo Imperio como mueble confortable destinado a la tertulia. Se trata de asientos con el respaldo bajo o incluso sin él, como es el caso de los "poff" o los "bornes", destinados a facilitar el asiento de las damas vestidas con las aparatosas crinolinas típicas de la época. Las pequeñas butacas totalmente acolchadas con sus respaldos en "capitoné" y rematadas en ricas pasamanerías, flecos o borlas constituyen un mueble nacido y característico del estilo Napoleón III.

\section{EPILOGO.}

La extremada calidad y belleza de muchas de las piezas de mobiliario del periodo Napoleón III es indudable, pero también es una realidad que se fabricaron grandes cantidades de muebles en calidades media y baja. Esta circunstancia afecta en general a las Artes Decorativas generadas en este periodo. Es una consecuencia de la industrialización y de la gran demanda social habida en la segunda mitad del siglo XIX.

Durante años, el estilo Napoleón III ha carecido de reconocimiento póstumo por parte de expertos, anticuarios y coleccionistas. El motivo que hay para que las piezas del Segundo Imperio tengan tan escasa valoración es principalmente, la carencia de originalidad en sus diseños por tratarse en su mayoría de reproducciones o inspiraciones surgidas a partir de muebles de otros periodos. En ocasiones el resultado era demasiado ecléctico o exageradamente pomposo. También reducía su interés el proceso industrial por el que habían pasado la mayoría de estas piezas. La abundancia de muebles y objetos industrializados procedentes del periodo Napoleón III ha saturado igualmente el mercado de las antigüedades.

Estas circunstancias han otorgado un papel "segundón" a muchas de estas tipologías en la Historia del Diseño. Por otro lado, la línea más "comercial" del Napoleón III, excesivamente reproducida e industrializada vulgarizó muchos de los prototipos del periodo contribuyendo con la comprometida fama del estilo. Esta circunstancia se repite con los opulentos espacios interiores realizados durante el Segundo Imperio, cargados en exceso de elementos ornamentales de diferentes estilos, mezclados con barroquismo teatral y sin criterio histórico, consiguiendo unos interiores excesivos, pero a su vez, representativos de la era de la industrialización.

Hoy en día, la valoración que se hace por parte de expertos y coleccionistas de muchas de las piezas y mobiliario nacido durante el periodo Napoleón III es más justa, otorgándoles una consideración superior atendiendo a sus propios valores y circunstancias. 


\section{LA EMPERATRIZ DECORADORA.}

Claramente la Emperatriz Eugenia era el eje estético del Imperio. Tenía "asignado" este papel desde que subió al trono en 1853 tras su boda con Napoleón III, quién desde un principio dotó a Eugenia con el imperial protagonismo que le llevó a ser el centro de la vida social de París y de toda Francia. Con un papel perfectamente medido desde el principio, Eugenia fue el origen de las modas y tendencias, así como elemento difusor de todas ellas. Considerado icono del estilo, del buen criterio, elegancia y centro de la brillante sociedad parisina, Eugenia era la imagen más palpitante del Segundo Imperio. Con una impecable labor de difusión mediante la prensa, grabados y folletos, gracias al pujante ferrocarril París era una ciudad atractiva y visitada; las obras de Winterhalter, las exposiciones internacionales, los bailes de las Tullerías, las noches de ópera o las acuarelas de Eugene Lami, Henri Baron o Fournier captando la belleza de la vida de la corte, divulgaron la imagen fastuosa del Imperio con Eugenia sentada en su trono. Francia pronto fue admirada e imitada por medio mundo.

La Emperatriz intervino activamente en la decoración de las residencias que habitó, así como en la selección de su mobiliario, llegando por ello algunos autores a insinuar la posible existencia de un "Estilo Eugenia". Se involucró en los trabajos de decoración realizados en los castillos de Compiègne, Saint Cloud o su particular Villa Eugenia en Biarritz, lugares donde se sentía muy feliz según sus propios recuerdos. Tras la caída del Segundo Imperio, Eugenia dirigió personalmente las obras de rehabilitación y decoración de las casas en que pasaba su vida. Sin haber llegado a tener un estilo especialmente diseñado para ella, sin embargo, sus gustos y criterio forjaron muchas de las modas seguidas durante el Imperio. Las preferencias personales de Eugenia tanto en mobiliario como en decoración terminaron por ser imitadas en medio Mundo y forjando la base estética del Estilo Napoleón III.

Siendo anciana la Emperatriz, le gustaba recordar sus primeras "hazañas" como decoradora de interiores, así como el gusto que esto le aportaba. Aún soltera, instalada en Paris con su madre la condesa de Montijo en mayo de 1851, escribe a su hermana Paca: ..." Tenemos un piso delicioso, en el número doce de la plaza de Vendôme que da sobre un gran patio. No se oye el menor ruido y parece que estamos en el campo" ... La propia Eugenia se decidió a arreglar la casa cambiando almohadones, cortinas y tapetes para conseguir hacerla más acogedora. Al no gustarle los cuadros existentes decide cambiarlos, sustituyéndolos por acuarelas pintadas por ella misma. Se sentía orgullosa del resultado hasta que una de las innumerables visitas que su madre recibía les preguntó: "Están ustedes de alquiler, ¿verdad?”, “por qué lo dice?” preguntó Eugenia con curiosidad. A 
lo que el visitante respondió: “¡Por los horribles cuadros que penden de las paredes!". La Emperatriz, solía reír contando esta historia.

\section{LAS CASAS DE LA EMPERATRIZ.}

La pareja imperial desde su matrimonio mantuvo los tradicionales traslados de la corte a los emplazamientos designados según la temporada, siguiendo con ello las regias costumbres de la Corona Francesa. Aunque su residencia considerada "oficial" era el castillo de Compiègne, el calendario político marcaba un recorrido por distintos palacios y reales sitios. El conjunto de edificios fue nuevamente decorado para adaptarlo a la imagen y gustos del Segundo Imperio. Dada la universalidad estética y en parte "historicista" del estilo Napoleón III, la adaptación de salones y dependencias usadas en los edificios de la Corona, consiguió con facilidad la imagen deseada. Atendiendo a estas necesidades de la Casa Imperial se multiplicaron los encargos de mobiliario tanto a ebanistas como a marcas comerciales, adquiriéndose igualmente alfombras o cortinajes, así como todos los elementos necesarios para componer los suntuosos interiores requeridos por la vida de la Corte Imperial. Igualmente, se recuperaron piezas pertenecientes a etapas del pasado que venían de anteriores reyes y reinados, para incorporarlas en la vida cotidiana. Todo este ambiguo conjunto de estilos y épocas se dispuso en las antiguas dependencias palatinas que en otras épocas habían sido ocupadas por los depuestos borbones, recuperando con ello espacios barrocos o neoclásicos, adaptándolos al opulento y brillante estilo Napoleón III. Todo ello, todos estos trabajos se desarrollaron bajo la supervisión de la Emperatriz.

Como expone el biógrafo de Eugenia, William Smith, se seguía "una especie de ritmo"...

..." Se instalaban a finales de diciembre en la Tullerías para un periodo de bailes y grandes fiestas. Por año nuevo, recibían a todos los embajadores, luego, en las fechas establecidas, los cuerpos constituidos acudían a felicitar al Emperador o a recibir sus mensajes. En el mes de mayo, la corte se trasladaba a Saint Cloud, una de las residencias preferidas por la emperatriz, a la que guardó mucho apego. Desde allí, a veces iban a pasar unas semanas a Fontainebleau. A partir del año 1856, aconsejados por los médicos, el emperador que padecía reuma y después de 1861, la piedra (lo que era mucho más grave) iba a tomar aguas a Vichy o a Plombières" ...

Era en este momento de tratamientos y toma de aguas termales de Napoleón, cuando la Emperatriz se desplazaba a su particular villa Eugenia en Biarritz, para 
tomar sus baños de mar compartiendo días de intimidad familiar con parientes y amigos.

Concluido este periodo de vida privada de los emperadores, la Corte Imperial recuperaba su agenda.

Continuando con la narrativa de Smith:

..." A principios de octubre regresaban a Saint Cloud, pero sólo para unos días, antes de instalarse en Compiègne. La temporada de caza reunía a toda la corte, y las formalidades de la etiqueta recuperaban su lugar. De hecho, Compiègne se convirtió en el palacio oficial de la corte de Napoleón III, y allí es dónde se suele enmarcar aquella vida brillante que contrasta tanto con el ambiente en la corte de Luis Felipe. En Compiègne se podía recibir a un centenar de huéspedes, pero raras veces se acogía a más de setenta. El ferrocarril facilitó el trayecto: Trenes especiales traían a los invitados en menos de dos horas. La emperatriz era la encargada de organizar aquellas recepciones" ...

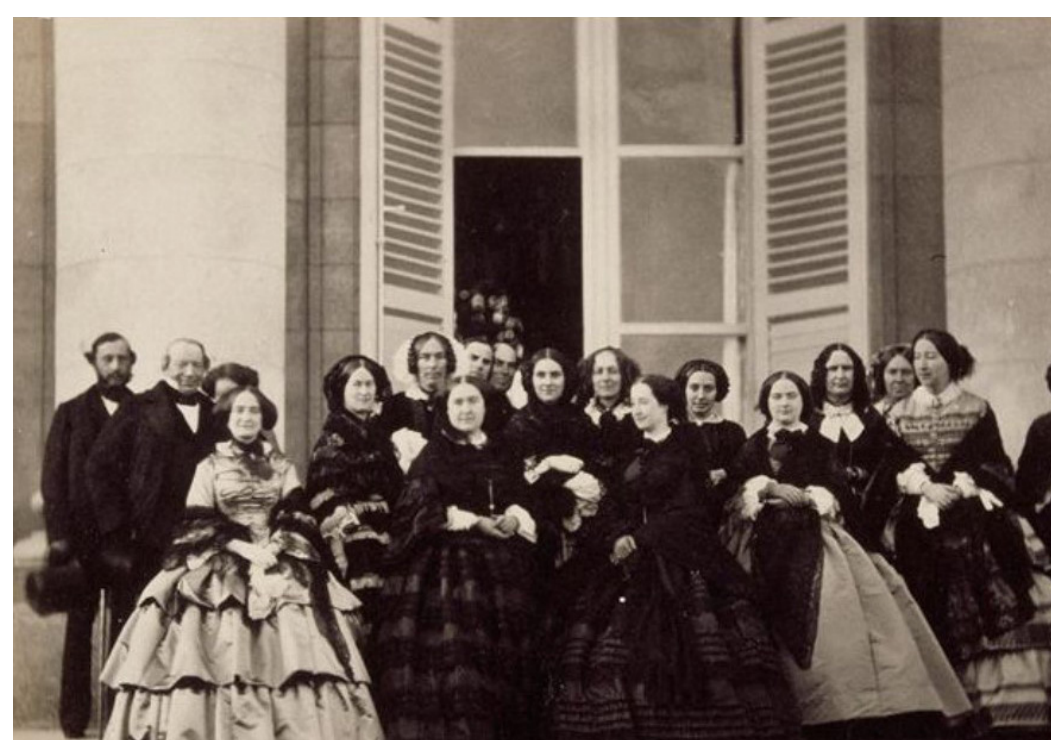

“Eugenia y sus damas en Compiègne”. Olympe Aguado.

Por tanto, las residencias de la Corte Imperial se repartían entre Compiègne, Saint Cloud, las Tullerías en Paris y el castillo de Fontainebleau. En el castillo de Saint Cloud, la Emperatriz ocupaba por decisión propia las mismas habitaciones que en su día pertenecieron a la Reina María Antonieta, donde vivía rodeada de sus recuerdos y obsesionada por que el destino no le llevase al mismo final que a la malograda soberana de Francia. En la correspondencia personal de la Emperatriz se recogen contadas por ella misma, algunas de las practicas de espiritismo que 
Eugenia realizó en esas habitaciones al igual que lo había hecho anteriormente la propia María Antonieta.

Algunas las fastuosas celebraciones organizadas durante el Segundo Imperio se festejaron en otros entornos palatinos como el Louvre ó en Versalles. La brillante recepción organizada en honor de la reina Victoria de Inglaterra en 1855 tuvo lugar en la ópera de Versalles, momento que se recoge en la acuarela realizada por Eugène Lami. Los apartamentos privados de Napoleón III en el Louvre son un excelente ejemplo de la opulencia ornamental de este periodo. Construidos entre 1852 y 1857 por el arquitecto Louis Visconti (1791-1853) a quien sustituyó Héctor Martín Lefuel (1810-1882) en 1853, están situados en el ala del edificio que habitara Richelieu en el siglo XVII y, guardan en su interior un grandioso proyecto espacial compuesto por una rica decoración y un amplio conjunto de mobiliario característico de la época.
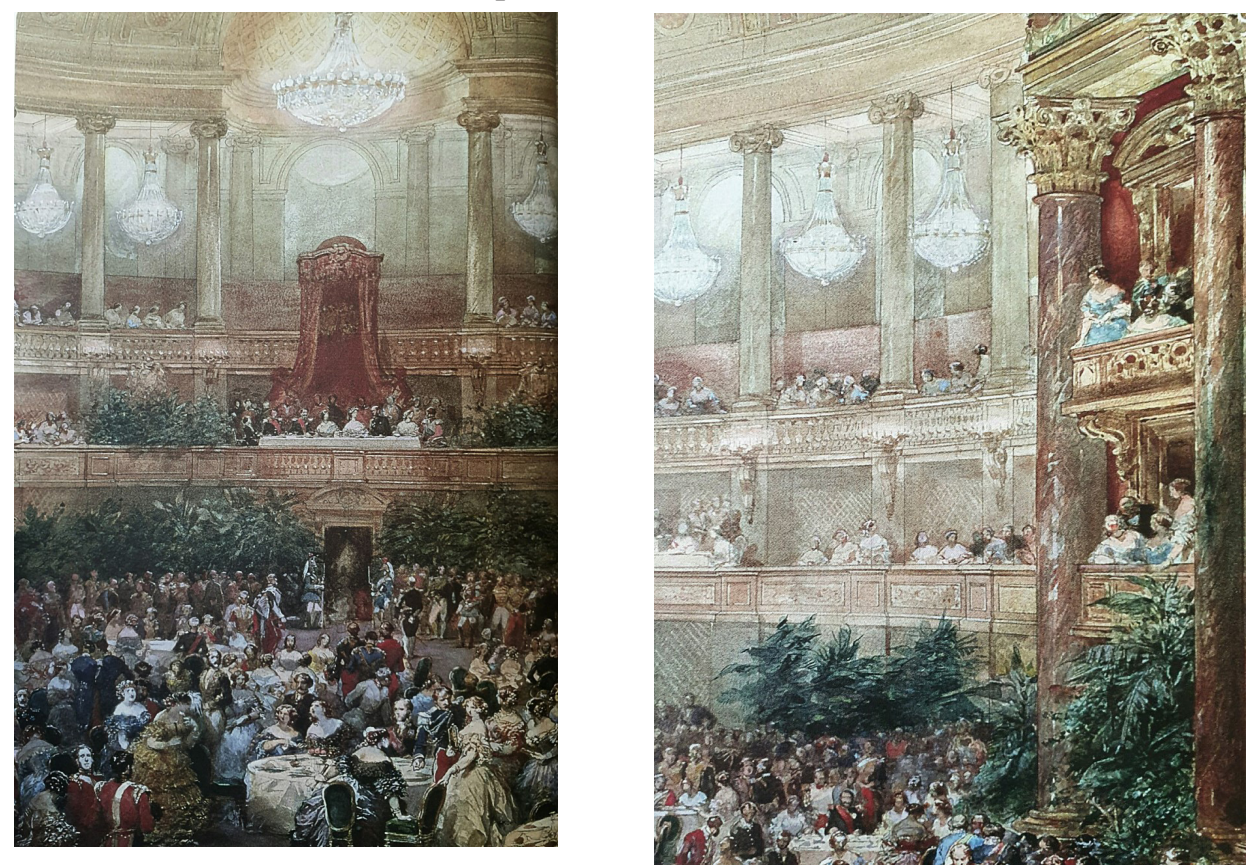

"Recepción ofrecida en honor de la Reina Victoria en la ópera de Versalles en 1855. Obra de Eugène Lami.

Desgraciadamente, tanto el castillo de Saint Cloud como las Tullerías sufrieron la suerte de la barbarie humana siendo totalmente destruidos con la caída del Segundo Imperio. Las Tullerías, incendiado por la Comuna de París el 24 de mayo de 1871 quedó prácticamente arrasado. Afortunadamente antes del incendio el personal de palacio consiguió retirar de salones y estancias oficiales, las piezas de mobiliario y obras de arte más valiosas logrando ponerlas a salvo en el vecino palacio del 


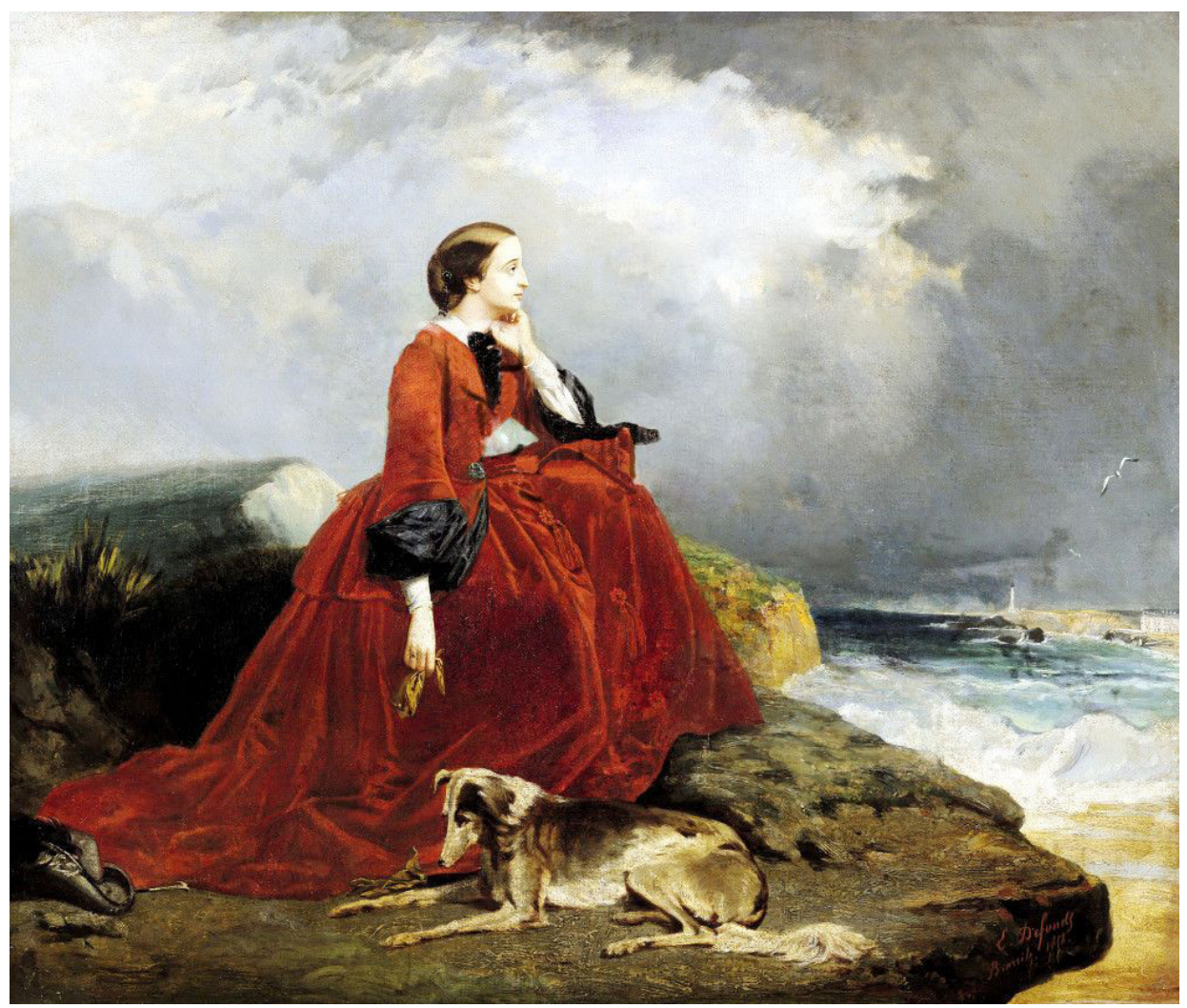

Emperatriz Eugenia en Biarritz. Retratada por E. Defonds en 1858. Fundación casa de Alba, Madrid.

Louvre. El propio Louvre se salvó milagrosamente de correr la misma suerte que las Tullerías. En 1883, el régimen republicano francés decidió demoler las ruinas que quedaban de lo que en su día había sido el flamante palacio de las Tullerías. El castillo de Sanit Cloud fue víctima de la Guerra Franco Prusiana, accidentalmente alcanzado por los bombardeos de 1871 que terminara él. Los restos que subsistieron a los incendios y bombardeos del palacio fueron pasto de saqueos y pillaje. En 1892 el Gobierno de la República Francesa ordenó la demolición definitiva de las ruinas.

Ya anciana la ex emperatriz de los franceses escribía:

“... Tengo muchas ganas de volver a ver Fontainebleau y Compiègne, que según dicen están como cuando vivíamos allí. Las Tullerias y Saint Cloud no son más que ruinas ya, pero allí también quisiera buscar huellas de todo un pasado enterrado bajo escombros."

La Villa Eugénie es sin duda uno de los caprichos de la Emperatriz. Desde pequeña había tomado baños de mar en Biarritz lo que le unió intimamente a esta 
costa. En 1854 comenzó la construcción de la villa encomendada en primer lugar al arquitecto Hippolyte Durand quien terminó las obras en tan solo diez meses, siendo inaugurada en 1855. Posteriormente Auguste Lafolye hizo una serie de reformas para ampliar el edificio. La Emperatriz, se involucró mucho en el proyecto siguiendo los cánones del estilo Napoleón III en su versión más simple y cercana al estilo Luis XVI. Sin apenas protocolos, esta villa fue uno de los lugares donde más feliz se sintió Eugenia durante los años del Imperio. Con la muerte del emperador en 1873, la villa pasó a ser propiedad exclusiva de Eugenia quién, en 1880 la vendió al Banco de la Unión de Paris. Desde 1893 el edificio alberga el elegante Hôtel du Palais, lugar donde el recuerdo de Eugenia aún habita...

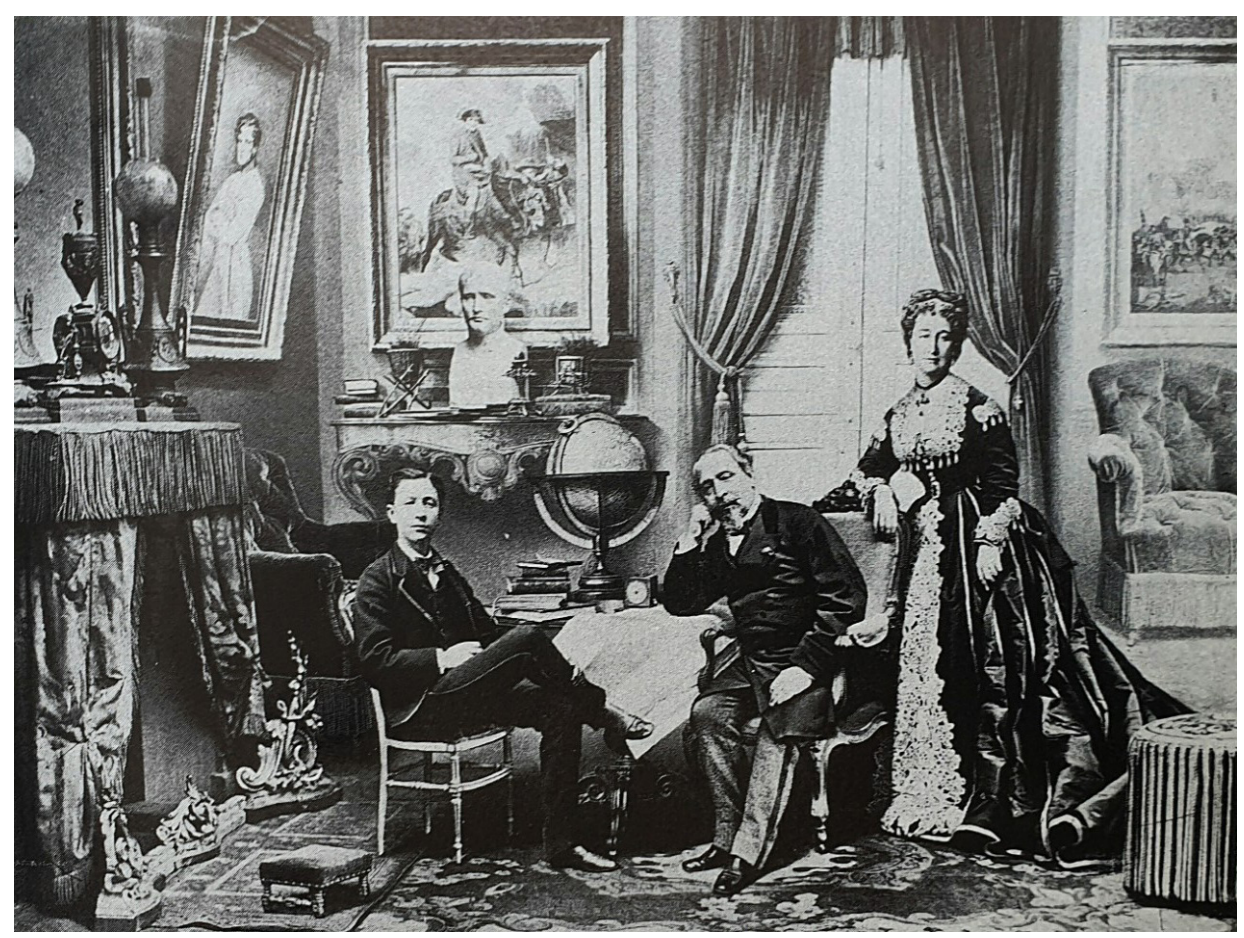

La familia de Napoleón III en Canden Place, 1871

\section{LAS CASAS DE EUGENIA}

\section{Canden Place}

Con la caída del Segundo Imperio en 1870, Napoleón y Eugenia junto con el Príncipe Imperial se reunieron en Inglaterra donde instalaron su residencia en el exilio, bajo el amparo de su querida amiga la Reina Victoria. Se establecieron en una pequeña casa de campo llamada Canden Place en Chislehurst cerca de Bath, donde Eugenia llego a vivir durante quince años. La casa era amplia, estaba divi- 
dida en dos plantas, pero como describen los que la visitaron, estaba lejos de ser la residencia de un príncipe siendo más apropiada para "....un pequeño hidalgo inglés..."

Según descripción escrita del dramaturgo Octave Feuillet (1821-1890):

“...Un pequeñísimo vestíbulo; luego una galería con muebles confortables con un hueco que parece una capillita. A mano derecha, la escalera, muy sencilla; a mano izquierda, la puerta del salón, que ofrece un lujo común. La chimenea es de mayólica con figuras en relieve. Una mesa redonda delante de la chimenea con periódicos diseminados por doquier. ¡Ya nada más! En cuanto al comedor, es de una sencillez provinciana: los periodistas que describen esta casa como un palacio son unos mentirosos o gente que nunca vió un palacio y ni siquiera un salón.”

En esta casa vivió la ex Emperatriz hasta 1885.

Son escasas las imágenes que de los interiores de Canden Place se conservan y que muestran los espacios tal y como los habitaban el ex Emperador y su familia. En la imagen que representa a la Familia Imperial en 1871 en su salón de Canden, observamos que la dependencia estaba arreglada y vestida al gusto francés, con importantes cortinajes, pasamanerías, alfombras y pequeñas butacas tapizadas que llenan el espacio siguiendo un orden destartalado. Sobre las paredes enteladas cuelgan pinturas y retratos de los Bonaparte, especialmente del Emperador Napoleón I que constituían parte de la herencia que el ex Emperador recibiese de su madre, la Reina Hortensia.

\section{Farnborough Hill}

Quizá el proyecto en que más cariño y entrega puso la ex Emperatriz de los Franceses fue en su nueva y definitiva casa: Farnborough Hill, en Hampshire, la que empezó a habitar en torno a 1881.

Una vez fallecidos el Emperador y el Príncipe Imperial, los recuerdos torturaban a la solitaria ex Emperatriz lo que le hizo insoportable la vida en Canden Place y le llevó a buscar una nueva residencia.

Eugenia, con gran motivación se puso al frente de las reformas del edificio supervisando personalmente su ampliación, estando pendiente de los más mínimos detalles como se desprende de la correspondencia mantenida con la Reina Victoria. Pero las obras no avanzaban al ritmo esperado lo que supuso la desesperación de Eugenia obligándole a alquilar una pequeña casa vecina a Farnborough Hill, 
Coombe Cottage, donde residir mientras terminaban las obras y poder vigilar directamente el ritmo de los trabajos.

Con el paso del tiempo, Eugenia había recuperado muchas de sus propiedades personales y objetos dejados en Francia tras su precipitada huida de las Tullerías en 1870 .

En palabras de John Bierman, biógrafo de Napoleón III:

“... A medida que pasaron los años y cicatrizaron las heridas dejadas por el Segundo Imperio, el Gobierno Francés gradualmente permitió que Eugenia recobrase gran parte de su propiedad personal, lo que permitió mejorar la lujosa residencia de Farnborough, así llegaron a sus manos retratos de familia de Winterhalter y otros pintores de la corte, un conjunto de paneles de Gobelin, sillas Luis XVI, vasos de Sèvres y otras cosas por el estilo. A su vez, Eugenia donó al Museo Nacional de la Malmaison una importante colección de recuerdos del Primer Imperio, legados por Hortense a Luis Napoleón"

Con respecto a sus muebles y el retraso de las reformas acometidas en Farnborough Eugenia escribe a la reina Victoria:

“... La casa está en un espantoso desorden; mis pobres muebles están desgastados lo mismo que si se hubieran utilizado todo el tiempo. Aparte de los recuerdos, creo, en verdad, que ¡no fuese un buen negocio mandarlos traer desde tan lejos! Pero si se pudieran arreglar creo que me sentiría menos extraña en medio de mis muebles que si todo, la casa y lo demás, fuera nuevo para mí"

Muchos de estos muebles, servicios de mesa, porcelanas, pinturas familiares y en general objetos personales y domésticos recuperados por la ex Emperatriz, los había hecho traer directamente a Farnborough procedentes de la recién vendida Villa Eugénie en Biarritz. Con todo ello, Eugenia consiguió un nuevo hogar cargado de recuerdos de su propia historia. Tal como ella misma organizó los interiores de Farnborough permanecieron intactos hasta su muerte en 1920.

Pero, dejemos que la propia reina Victoria nos describa Farnborough con sus propias palabras tras su visita a la casa en 1884, según se recoge en la obra de William Smith sobre la Emperatriz Eugenia:

“... Se llega por un pabellón de entrada que la emperatriz mandó construir y se recorre un bonito parque hasta la casa, que tiene un aspecto imponente, con una torrecilla. Es un edificio de ladrillos blancos, con vigas y un desván encima de aguilones, en el antiguo estilo inglés. Tras cruzar el hall donde se encuentra el famoso cuadro de Winterhalter (que representa a la emperatriz con sus damas de honor, nos llevó a un pequeño salón acondicionado como cuarto de aseo, pero que es gabinete. Da a una encantadora salita de estar, que mandó añadir, con un gran ventanal que forma un hueco, y delante del cual plantó hierbas y otras plantas que 
trajo de Zululandia, al lado de violetas procedentes de Santa Elena. En medio se encuentra una estatua del querido Príncipe Imperial, de niño. Colgados de la pared hay: un retrato en pié muy hermoso del Emperador, un retrato con un magnífico parecido, y otros cuadros y retratos muy valiosos. La habitación da a otro saloncito con (palabra ilegible) y su retrato por Winterhalter. Hay un pequeño sofá tapizado de satén de color malva adornado con flores rosas (tela, me dijo la emperatriz), del último vestido que llevó en las Tullerias. Comimos en un hermoso comedor, al final del pasillo que mandó construir por completo; este comedor tiene unos cuantos cuadros hermosos, entre los que destaca el retrato de su hermana la duquesa de Alba, y la duquesa de Mouchy por Winterhalter, así como varios bustos de la familia Bonaparte. El comedor es amplio, con tapicerías, revestimiento de madera y un hermoso parqué. Después de la comida, la emperatriz nos hizo visitar las demás habitaciones de la planta baja. El gran salón con un retrato en pié de la reina Hortensia, así como, de los del rey Luis, de la emperatriz Josefina, de la emperatriz María Luisa etc. Y varios vestigios del pasado que salvaron por fortuna. Entonces, penetramos en la habitación que la emperatriz ha añadido y, que reproduce exactamente la forma y dimensiones de la del príncipe en Chislehurst, donde se guardan todos los objetos de su infancia, incluida una cuna muy bonita dada por la ciudad de Paris, su ropa, su espada y todo lo que utilizaba en Chislehurst."

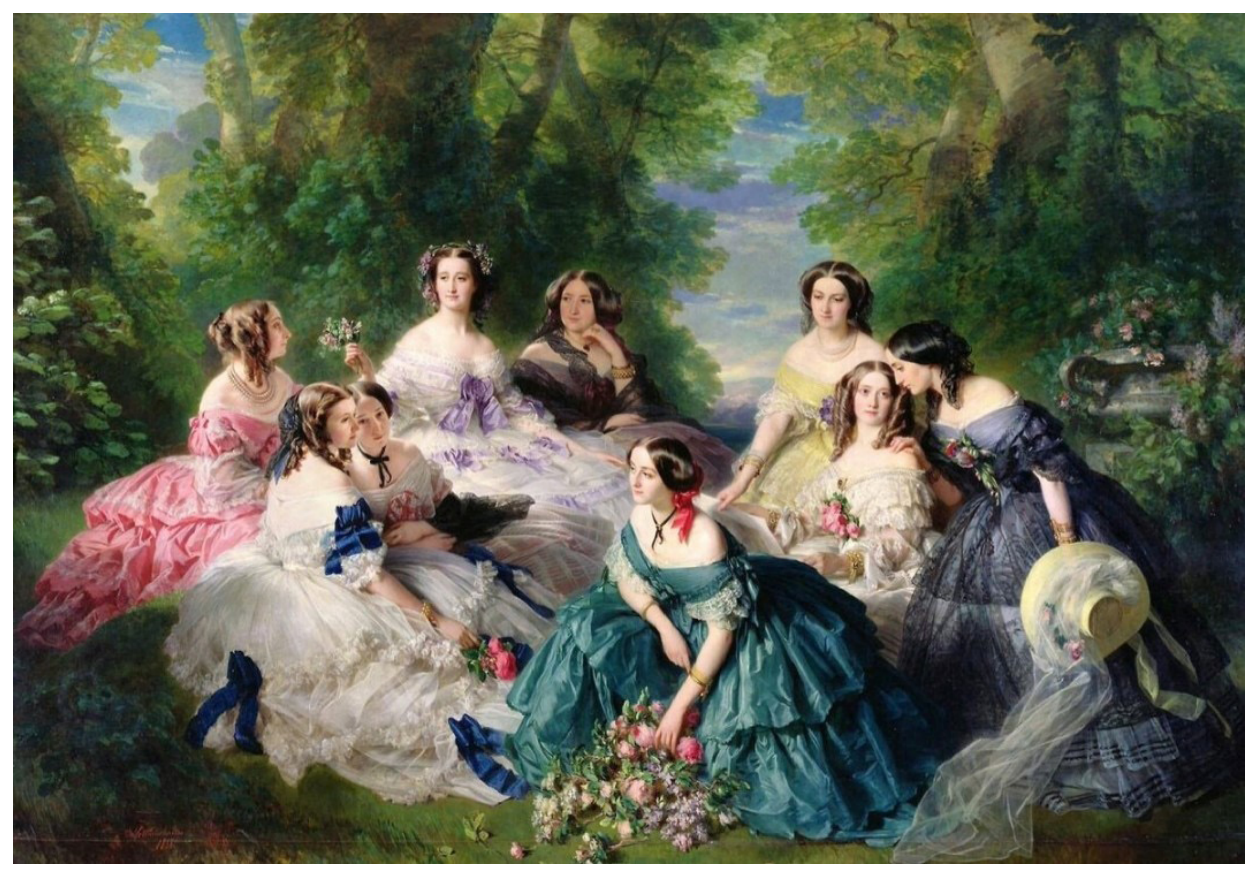

“La Emperatriz Eugenia y sus Damas”. François Xavier Winterhalter (1805-1873).

La Emperatriz había dedicado todas sus energías a las obras y decoración de su nueva casa lo que indiscutiblemente hizo con brillantez y buenos resultados culminando así su afición por el interiorismo. Recordaba entonces con humor, 
cómo en el lejano año de 1851 ella misma se había aventurado a decorar la casa alquilada por su madre, la condesa de Montijo, en el número 12 de la parisina Plaza Vendône organizando muebles, cortinas y tapetes.

En 1908, siempre atraída por las novedades y la modernidad, Eugenia mandó instalar luz eléctrica en Farnborough teniendo que realizar nuevamente importantes obras. No en vano siendo Emperatriz de los Franceses, Eugenia había sido uno de los pilares visibles de la Revolución Industrial, mostrando siempre un gran interés por las últimas novedades tecnológicas como la fotografía o el teléfono.

Parece que la ex Emperatriz rodeada de su pasado consiguió cierta paz personal en Farnborough Hill, según refleja en su activa correspondencia con la Reina Victoria. Aunque pronto la energía característica de su persona llevo a Eugenia a emprender un nuevo proyecto: Villa Cyrnos.

\section{Villa Cyrnos}

Cyrnos, era el nombre griego que recibía la isla de Córcega. Llamando así a su nueva villa, Eugenia dedicaba un pequeño recuerdo a los Bonaparte. La ex Emperatriz decidió buscar un lugar con un clima más soleado y amable que el de Farnborough para pasar largas y confortables temporadas. Por ello y tras mucho deliberar, adquirió los terrenos que consideró más apropiados para su objetivo situados en la Costa Azul, en Roquebrune, Cap Martín, entre Mentón y Montecarlo en un bellísimo paraje mediterráneo. Comenzó a edificar la villa en 1892. En-

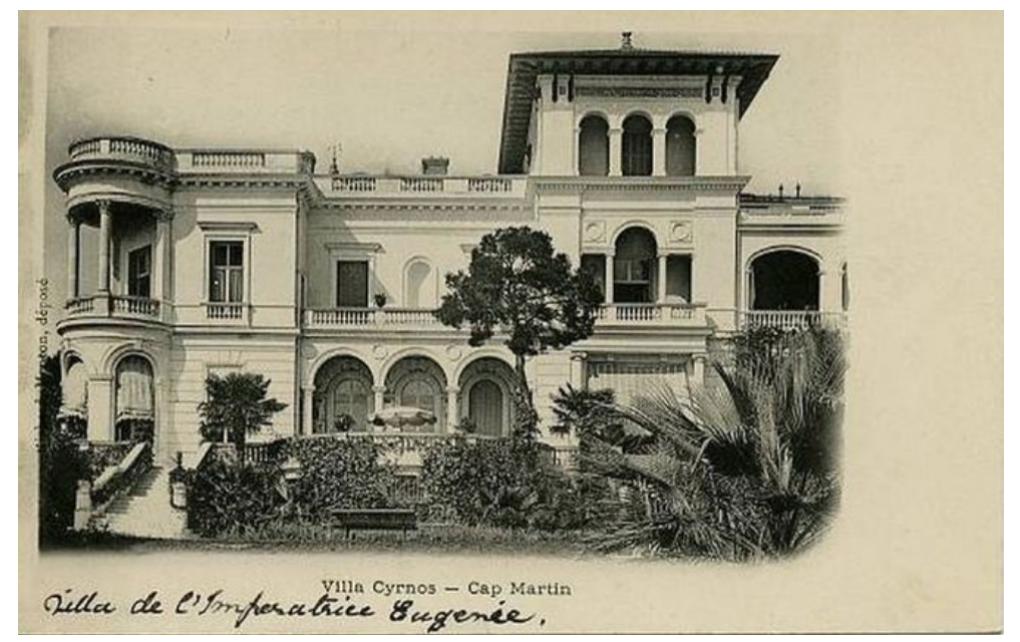

"Villa Cyrnos, Cap Martín”

cargó el diseño al arquitecto danés Hans Georg Tersling (1857-1920) que trabajaba habitualmente en la Costa Azul teniendo un estilo muy característico de la 
Belle Époque. Nuevamente, Eugenia se entregó de lleno al proyecto participando directamente en las obras y la decoración. Pero el ritmo de los trabajos no era el esperado por lo que la Emperatriz, se instaló en la casa en el invierno de 1894, aunque el edificio seguía en obras y lleno de operarios. Villa Cyrnos estuvo definitivamente terminada en la primavera de 1895.

Como describía John Bierman:

“... Tanto en Farnborough como en su segunda residencia, la Villa Cyrnos, (...) Eugenia vivió con gran estilo. Dijo un visitante frecuente: "Sus criados, la comida, todo el entorno recuerda una corte". Pero Eugenia solía retirarse del lujo de sus residencias en tierra firme y pasaba gran parte del tiempo en el mar, navegando en el Thistle, el pequeño yate de vapor, bastante incómodo y no demasiado estable".

Con el tiempo la ex Emperatriz se decidió ampliar la Villa Cyrnos con la construcción, dentro del entorno de su parque, de un nuevo pabellón destinado a alojar a sus numerosos invitados. Nuevamente Eugenia supervisó hasta el último detalle de la obra y no descanso hasta verla concluida. La nueva construcción fue bautizada con el nombre de "Teba" en recuerdo al condado de Teba, título usado por Eugenia hasta su matrimonio con Napoleón III.

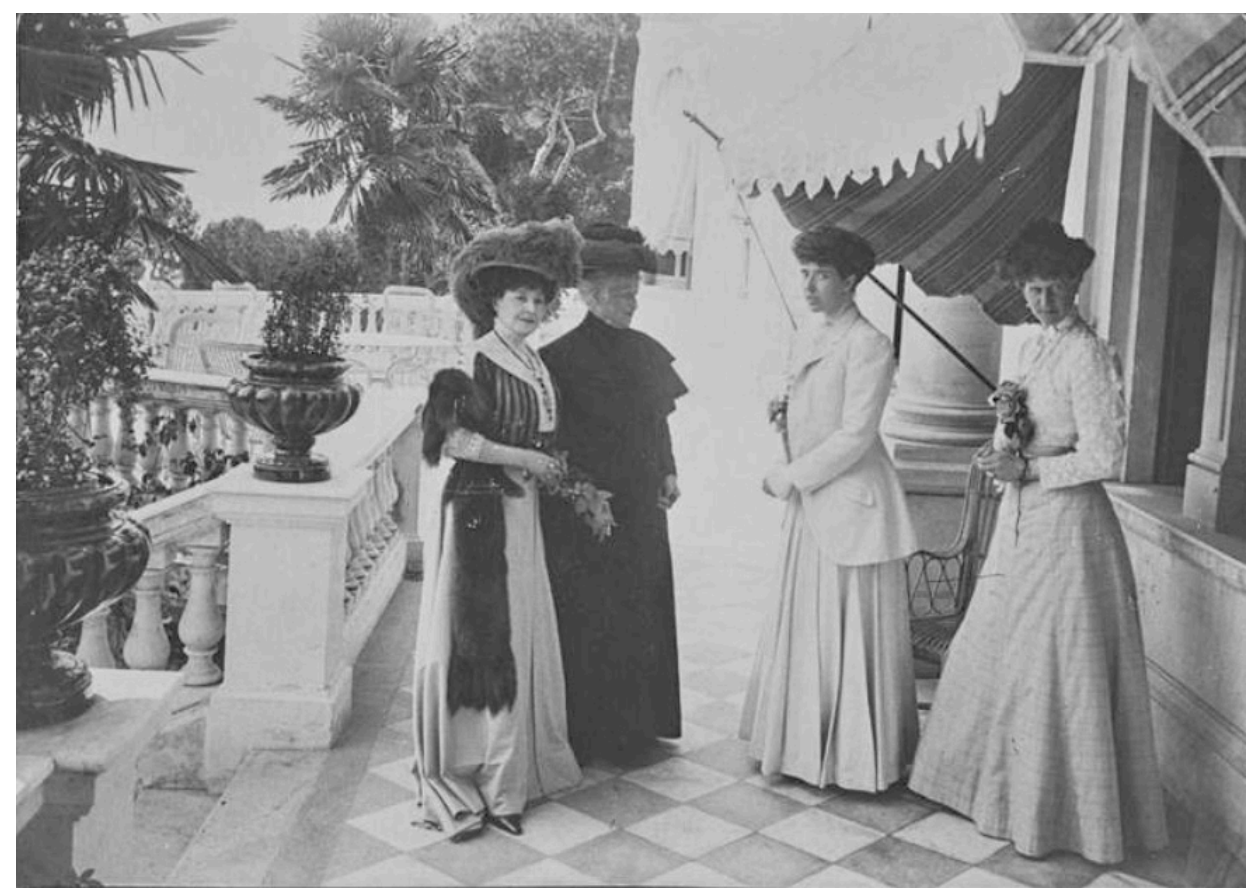

La Emperatriz Eugenia en la Villa Cyrnos 
Desde entonces y hasta su fallecimiento, la cálida luz de la Costa Azul acompañó a la Emperatriz que disfrutaba pasando largas temporadas en la Villa Cyrnos. Al igual que había hecho en Farnborough, decoró la villa con sus muebles, pinturas y recuerdos, todos ellos opulentos testigos del estilo Napoleón III. Convirtió esta pequeña villa en un lugar de reunión al que acudían sus familiares y fieles, rodeada de una pequeña corte en la que no faltaban sus amigas, la reina Victoria o la Emperatriz "Sisi" de Austria con las que había compartido vida e Historia.

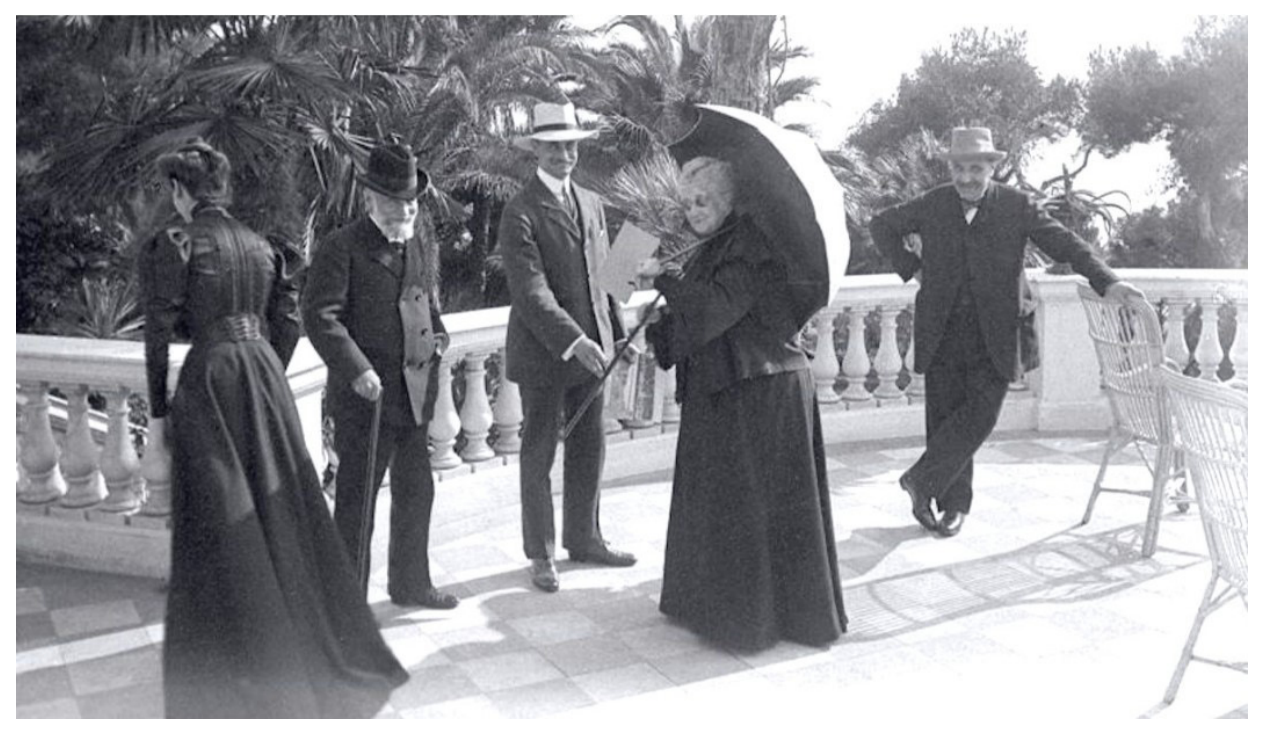

La Emperatriz Eugenia en la Villa Cyrnos

\section{LIRIA}

El Palacio de Liria se empezó a construir en Madrid en el año 1767 por encargo del Duque de Berwick al arquitecto francés Louis Guilbert, quién en 1771 fue sustituido por Ventura Rodríguez con la misión de concluir las obras. El cambio de arquitecto fue debido a ciertas irregularidades en la construcción y en las cuentas, lo que llevó al Duque a pedir al afamado Rodríguez que pusiera orden y concluyese el edificio. En el siglo XIX este bonito palacio de estilo neoclásico era habitado por los Duques de Alba y Berwick que habían unido sus linajes mediante alianzas matrimoniales. Paca, la querida hermana de la Emperatriz Eugenia se había casado en febrero de 1844 con el XV Duque de Alba de Tormes, lo que le llevó a habitar en el Palacio de Liria.

Quiso el destino que esta incansable mujer que era la Emperatriz Eugenia, con una vida romántica llena de recorrido y paradojas, terminara sus días en el Palacio de Liria de Madrid en la madrugada del 11 de julio de 1920, rodeada de su propia sangre, en la que había sido habitación de su hermana Paca. 


\section{DOCUMENTACIÓN.}

La política seguida por el gobierno de Napoleón III de difundir la fastuosa y brillante imagen del Segundo Imperio nos ha legado importantes conjuntos de óleos, dibujos, acuarelas y obra gráfica que recogen momentos concretos del periodo y nos permiten analizar los espacios interiores tal y como fueron usados en la época.

Igualmente, la ampliación de París dentro de la reforma de Haussmann llevó a la realización de muchos proyectos de interiorismo, dibujos y planos destinados a hoteles o elegantes casas de viviendas en la avenue de l’Opera ó los Camps-Elysées y que igualmente hoy en día se conservan en colecciones o museos como el Museo de Artes decorativas de Paris ó Compiègne principalmente.

Los catálogos de los talleres de ebanistería o de las exposiciones internacionales aportan también, gran cantidad de datos sobre los espacios y mobiliario del periodo Napoleón III. Indiscutiblemente, es una época en el que la sociedad gustaba de tener buenos muebles y de vivir siguiendo los cánones estéticos de las modas de la época.

De estos proyectos de interiores que muchas veces se editaban, se guarda una buena colección en la biblioteca del Museo de Artes Decorativas de París, como las realizadas por Victor Quétin en 1860 para "le Magasin de meubles, Album de tentures no 9, Paris"

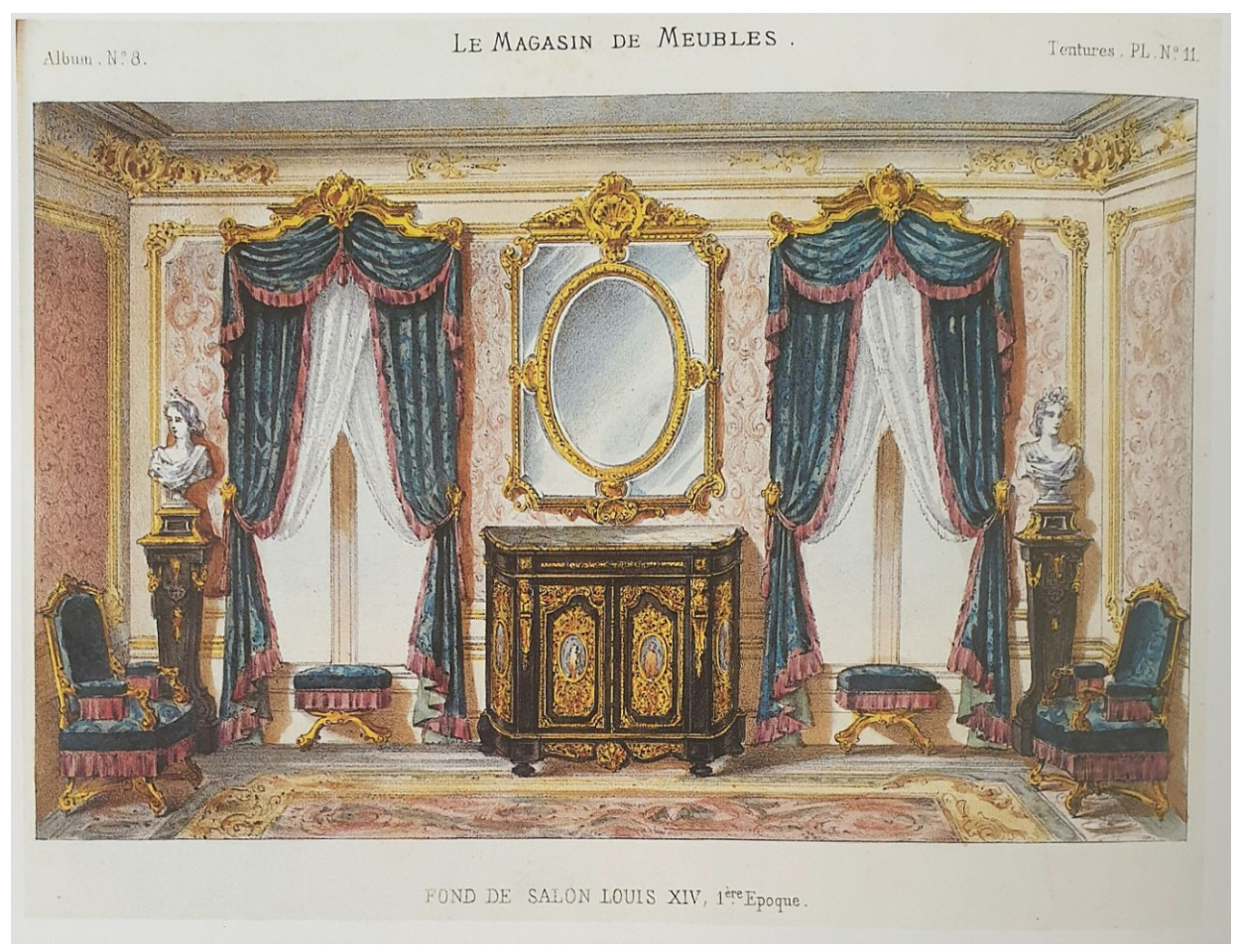


Muy destacable es el conjunto de obras realizadas para plasmar la brillantez con que se desarrolló en la visita de la Reina Victoria de Inglaterra acompañada del Príncipe Alberto a París en 1855 y que recogen diferentes momentos de las recepciones organizadas en el Hotel de la Villa de París o en la ópera de Versalles en honor de Victoria.

Igualmente, siguiendo la política de proyección internacional de la imagen del Imperio, son interesantes los trabajos de Henri Baron recogiendo los fastos organizados en las Tullerías con motivo de la Exposición Internacional de 1867 guardados en el castillo de Compiègne.

Quizá uno de los conjuntos más interesantes que se conserva es el grupo de pinturas que reproduce vistas interiores de las habitaciones de la Emperatriz Eugenia en Saint Cloud, pintadas por Fortuné de Fournier (1798-1864). Realizadas en 1860 recogen varios encuadres de los apartamentos usados por la Emperatriz. $\mathrm{Su}$ estudio es fundamental para analizar los gustos de Eugenia y reconstruir el estilo Napoleón III. El conjunto se conserva en el Museo Nacional de Compiègne.

También de los interiores de Saint Cloud, guardados en la biblioteca del Castillo de Windsor un conjunto de acuarelas, igualmente obra de Fortuné de Fournier realizadas en 1855 y que, representan a la Reina Victoria en el interior de las habitaciones que usó en el Castillo de Saint Cloud durante su visita a París en éste mencionado año.

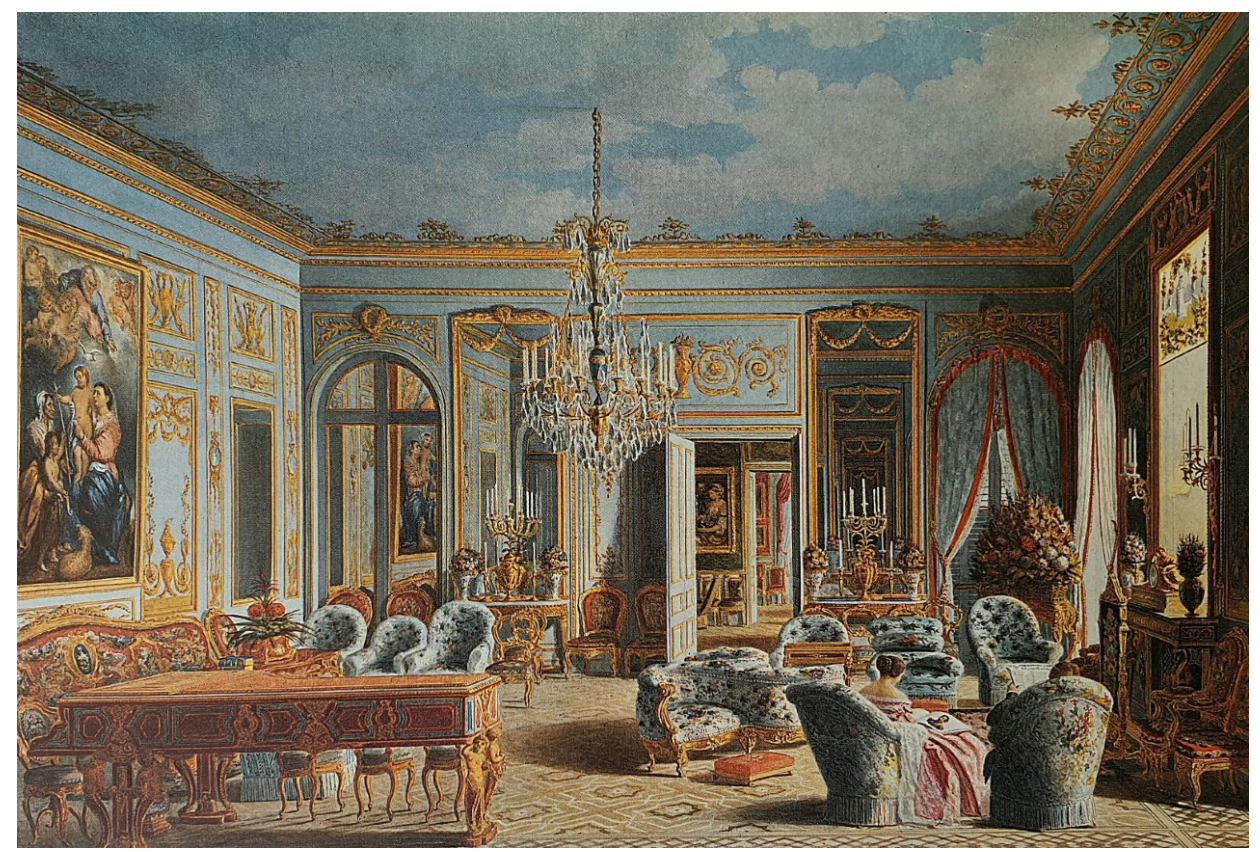




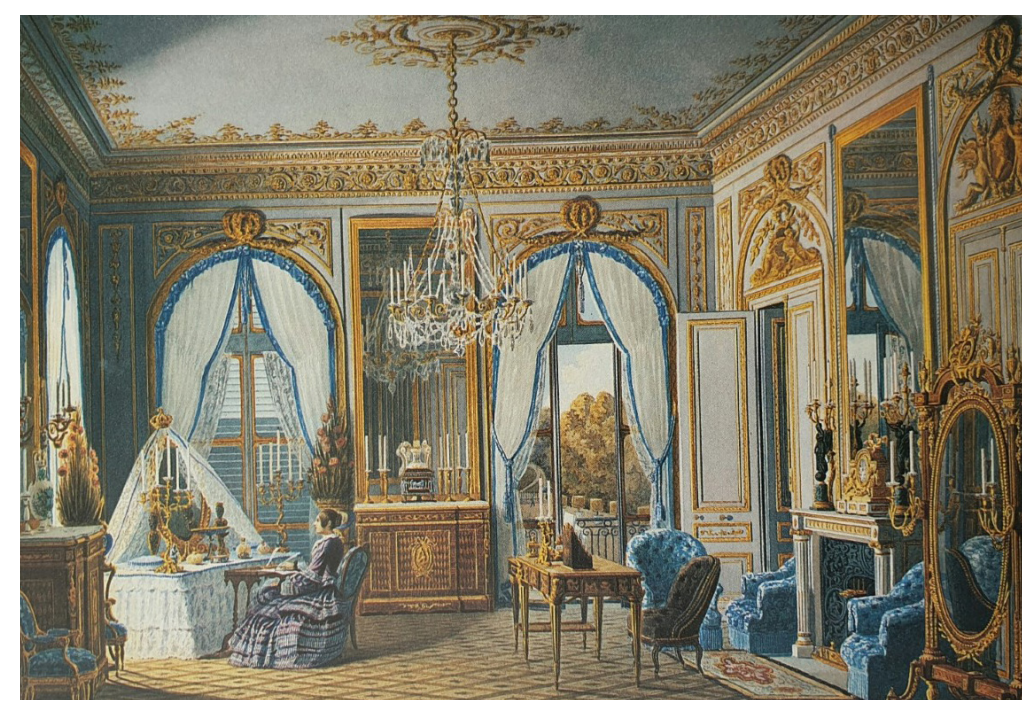

Un conjunto de gran interés es el que reproduce los interiores y salones del hotel situado en la rue de Courcelles en Saint Gratien, propiedad de la Princesa

Matilde Bonaparte, y que se conservan el Museo de Artes Decorativas de París. Matilde Bonaparte (1820-1904) prima de Napoleón III, era hija de Jerónimo Bonaparte que fuera rey de Westfalia durante el Primer Imperio. Muy interesada por las artes y gran coleccionista, mantuvo una importante actividad cultural en sus salones, reuniendo en las "soireé" que organizaba a los artistas y autores más destacados del Segundo Imperio. Ella misma tenía talento para la pintura. Su relación con la Emperatriz Eugenia era tirante, aunque curiosamente, fue en los salones de Matilde donde Napoleón conoció a la Condesa de Teba, futura Emperatriz de los Franceses.

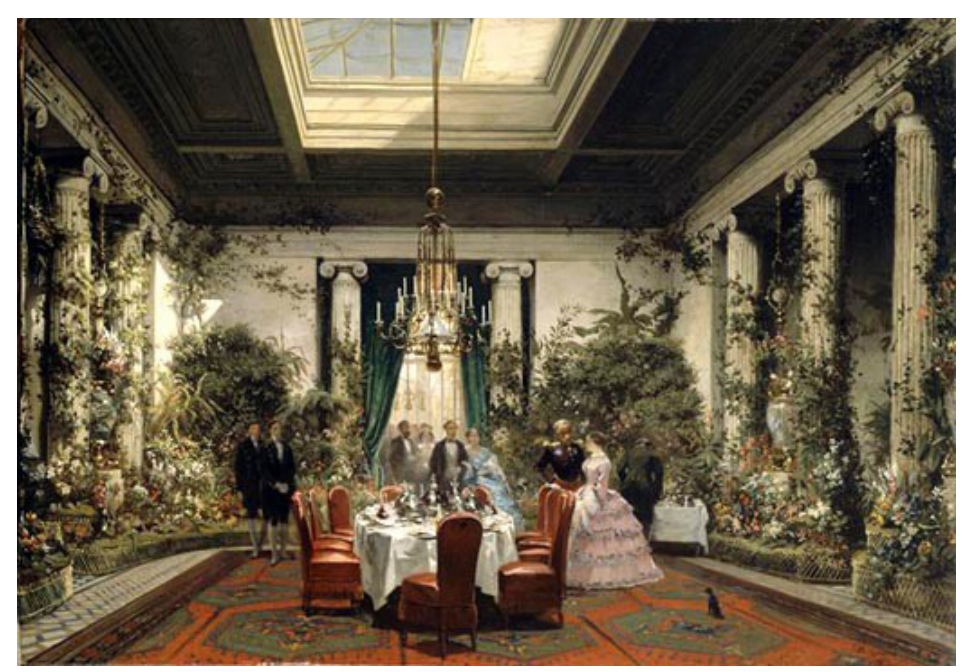


De este destacado e imprescindible conjunto de acuarelas destacan las realizadas por Charles Giraud (1819-1892) en 1867, que reproducen "Le salón de la princesse Mathilde" ó "Salle à manger de la princesse Mathilde, rue de Courcelles", "La vérenda de la princesse Mathilde", pintada por Giraud en 1870. Otras pinturas de Giraud, reproducen el atelier de la princesa realizadas en 1857 o 1863 , incluso en alguna de éstas obras aparece la propia Matilde trabajando en su taller.

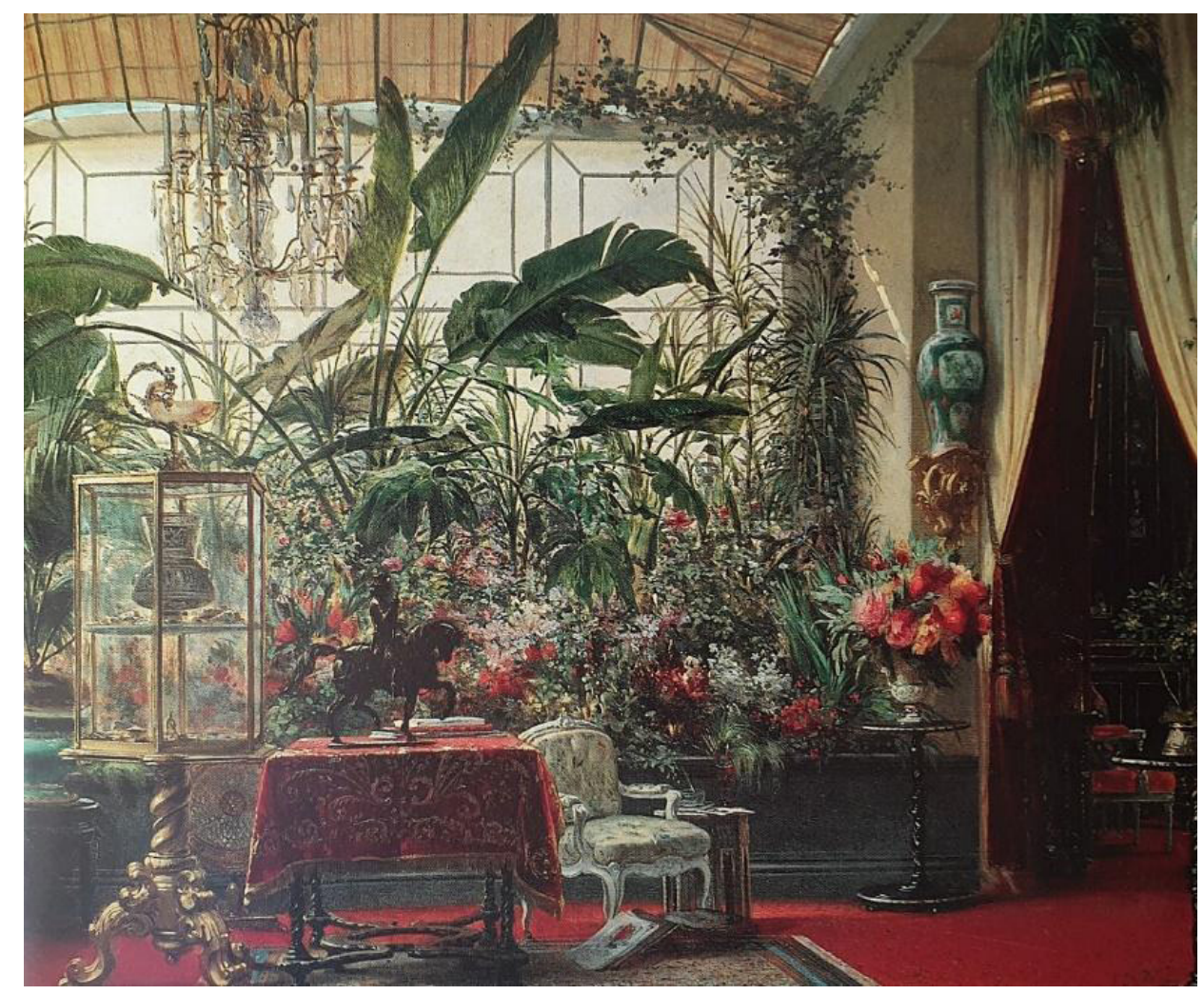

Quizá la más conocida de estas pinturas, también obra de Giraud (óleo sobre lienzo), realizada en 1859 es: "El Salón de la princesse Mathilde" que a diferencia de la obra anteriormente mencionada bajo éste mismo título y realizada en 1867, la de 1859 reproduce el salón de recibir de la Princesa con su concurrencia en una velada nocturna en la que aparece Matilde en el centro de la reunión, iluminada por la cálida luz de los quinqués. Igualmente ocurre con otra interesante obra del mismo autor: "Salle à mangar de la princesse Mathilde rue de Caurcelles" que, a diferencia de la pintada en 1870 bajo el mismo título, reproduce un espacio ataviado elegantemente para recibir a una serie de comensales para la cena. Estas dos últimas pinturas se guardan en el Museo Compiègne. Igualmente señalar que se trata de comedores y salones diferentes, aunque las obras tengan el mismo título. 
Del tristemente desaparecido Palacio de las Tullerías se conservan, guardadas en el Museo de Compiègne, unas acuarelas realizadas por Jean Baptiste Fortuné de Fournier en 1862, que representan "Le cabinet de travail de l'empereur Napoleón III aux Tuileries", "La salle du Conseil des ministres aux Tuileries" también realizada en 1862, aparece presidida por el maravilloso retrato de la Emperatriz de los Franceses obra de François Xaver Winterhalter (1805-1873).

En la colección de los Duques de Alba y Berwick, se conserva en el palacio de Liria de Madrid, un oleo sobre lienzo realizado por Giuseppe Castiglione: 'L'empératrice Eugénie dans son boudoir" que, en un espacio muy propio de mediados del siglo XIX, representa a Eugenia en su salón en las Tullerías.

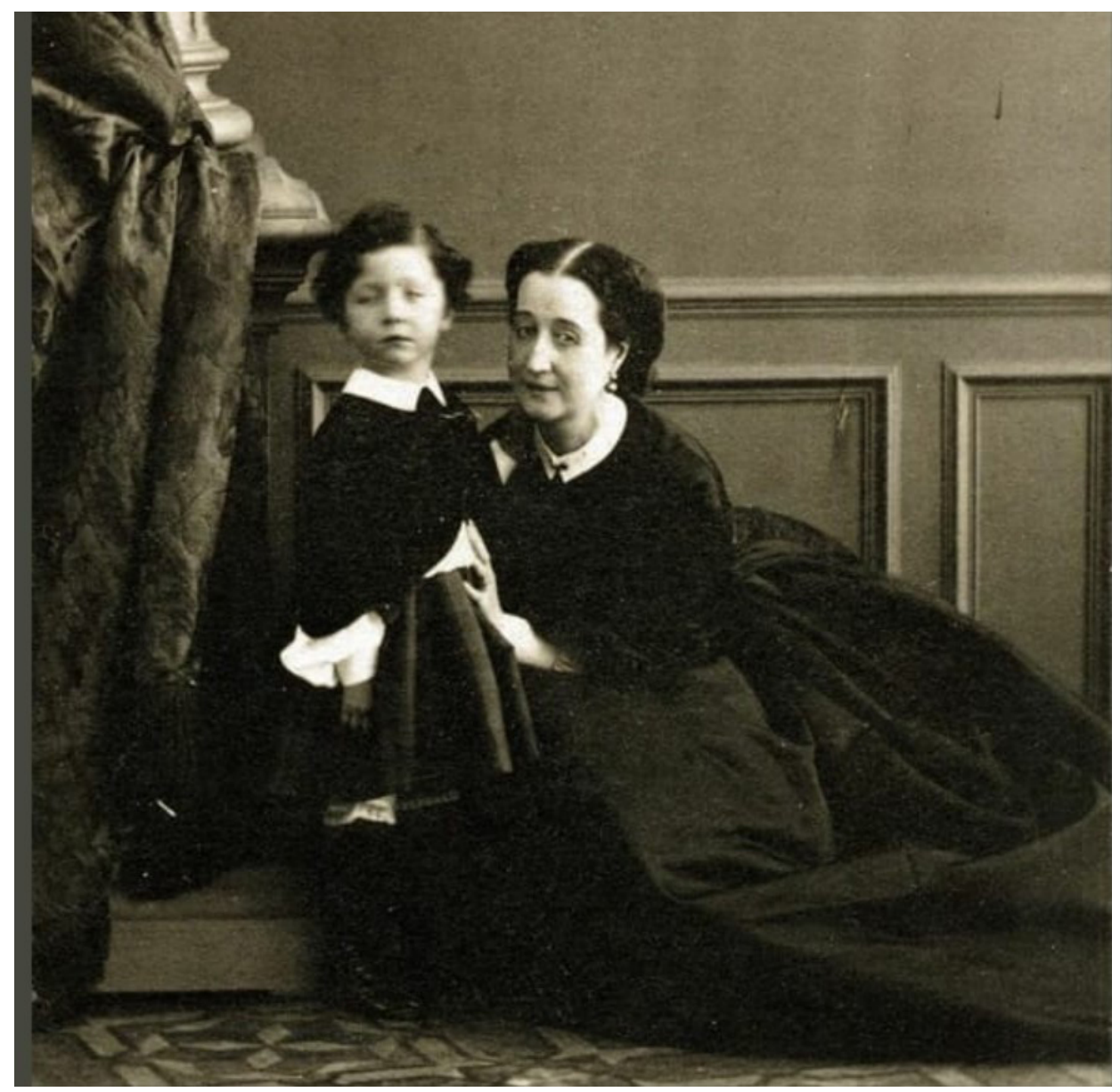

La Emperatriz Eugenia y el principe Imperial 


\section{BIBLIOGRAFIA}

Bierman, John: "Napoleón III y su alegre Imperio" Edt. Vergara. Buenos Aires, 1991.

Sagrera, Ana de: "La Juventud de la Emperatriz Eugenia" Edt. Compañía Literaria. Madrid, 1997.

Smith, William: "Eugenia de Montijo". Edt. Espasa Calpe, Madrid 1991.

AA.VV.: "Un soir chez la Princesse Mathilde. Une Bonaparte et les Arts". Silvana Editoriale \& Palais Fesch, Museé des Beaux-Arts. Paris, 2019.

Gere, Charlotte: "Nineteenth Century Decoration. The Art of the Interior". Edt. Weidenfeld \& Nicolson. London, 1989.

Nouvel-Kammerer, Odile: “Napoleon III. Années 1880”. Le Mobilier Français” Edt. Massin. Paris, 1996.

VV/AA: "El mueble del siglo XIX". Editorial Planeta-Agostini/Sotheby's. Barcelona, 1989.

Kjellberg, Pierre: "Le Meuble Français et Européen". Les Éditions de 1Àmateur. Paris 2011.

Fleming, John: "Diccionario de las Artes Decorativas" Alianza Editorial, Madrid 1977.

Kjellberg, Pierre: "Le Meuble Français et euroéen. Du Moyen Âge à nos jours". Edt. Les Éditions de L'Amateur, Paris 2011.

Fonkenell, Guillaume: "Le Palais des Tuileries”. Edt. Honoré Clair. Arles, 2010. 